Iranian Journal of Breast Diseases. $2021 ; 14(2): 26-40$.
Original Article

\section{Barriers to Participation of Breast Cancer Patients' Relatives in Mammographic Screening}

\author{
Noori $\mathbf{K}^{1}$ ، Sahraee $\mathbf{P}^{2}$, Keshavarz Mohammadi $\mathbf{N}^{3^{*}}$ \\ ${ }^{1}$ Islamic Republic of Iran Taekwondo Federation, University of Applied \\ Science and Technology, Tehran, Iran \\ ${ }^{2}$ Family Health Department, Kamyaran Health Network, Kurdistan University \\ of Medical Sciences, Sanandaj, Iran \\ ${ }^{3}$ Public health Department, School of Public health and Safety, Shahid \\ Beheshti University of Medical Sciences, Tehran, Iran
}

Receive: 9/3/2021

Accepted: 4/7/2021

"Corresponding Author:

n_keshavars@yahoo.com

Ethics Approval: IR.SBMU.PHNS.REC.1395

\begin{abstract}
Introduction: Breast cancer is the most common female cancer in the world and Iran and the leading cause of cancer death among Iranian women. One way to control this cancer is to get screened and diagnosed early. Given that screening in the general population is not possible, early detection of this cancer in high-risk women is one way to control it. Mammography is one way to diagnose breast cancer, but unfortunately, most people do not want to have a mammogram. This is an important issue for women with a family history of breast cancer, which constitutes one of the most high-risk groups for the disease. Therefore, the present study aimed to identify the views of relatives of patients with breast cancer about the reasons for unwillingness to perform mammography.
\end{abstract}

Methods: The present study was a qualitative study performed on 160 firstdegree relatives and 118 second-degree relatives of breast cancer patients who were selected by purposive sampling to discover the reasons for not performing mammography. In-depth semi-structured interviews were used to collect data. All data were recorded and handwritten and analyzed using structural methods.

Results: In the content analysis of the interviews, 5 themes, 14 main categories, and 73 subcategories were extracted. Preoccupation with daily life matters and lack of knowledge were the most common barriers to participation in screening among 1st-degree relatives, while wrong beliefs and attitudes constituted the most common barriers contributing to the unwillingness to getting mammography screening among 2nd-degree relatives.

Conclusion: Relatives of women with breast cancer are neglected despite facing a high probability of developing this cancer. It is suggested that the country's health system provide comprehensive and effective education for relatives of women with breast cancer to raise awareness and eliminate misconceptions.

Keywords: Breast Cancer, Mammography, Screening, Barriers, Relatives of Breast Cancer Patients 


\section{بررسى موانع انجام غربالكرى ماموكرافيك در بستكان مبتلايان به سرطان يستان \\ $1 \varepsilon \cdot \cdots ! 1 \varepsilon(r): \varepsilon \cdot-r 7$}

كبرى نورى'، يروانه صحرائى'، نسترن كشاورز محمدى "*" 'فدراسيون تكواندو، دانشكاه جامع علمى كاربردى، تهران، ايران

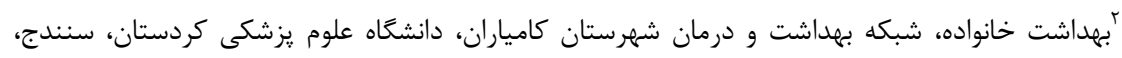
ايران "rكروه بهداشت عمومى، دانشكده بهداشت، دانشكاه علوم يزشكى شهيد بهشتى، تهران، ايران

فصلنامه بيمارى هاى بستان ايران

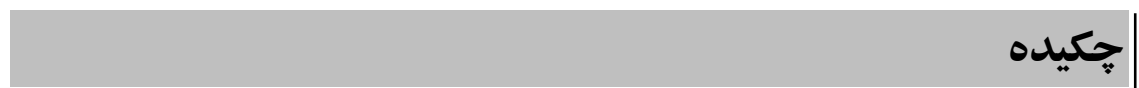

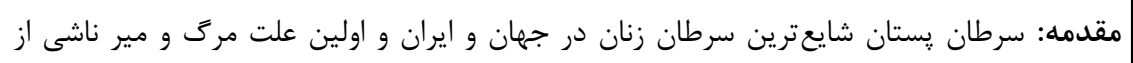

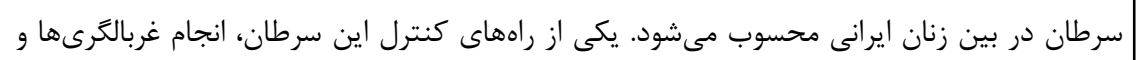

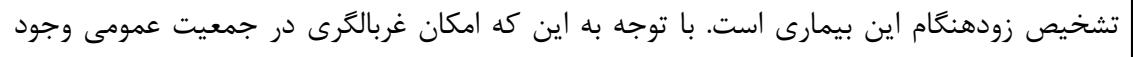

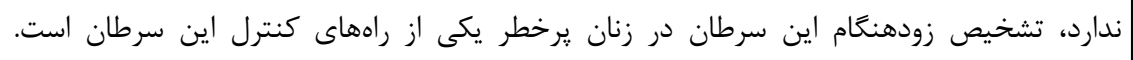

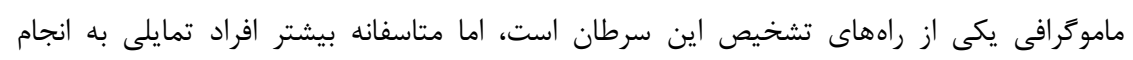

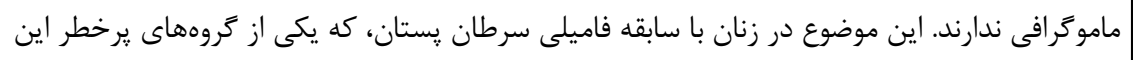

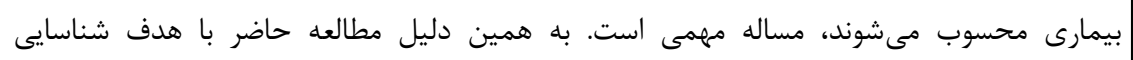

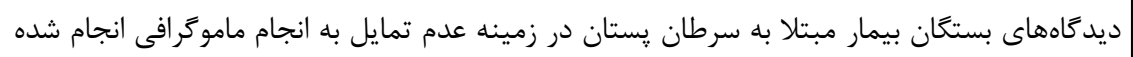

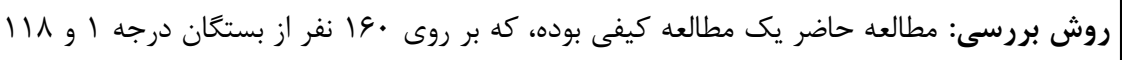

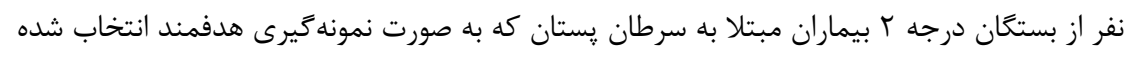

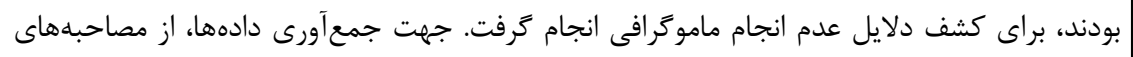

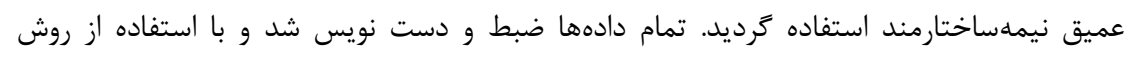
ساختارى مورد تجزيه و تحليل قرار ترفت.

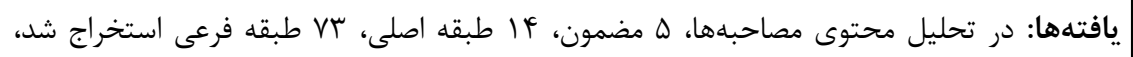

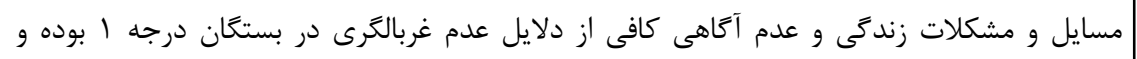

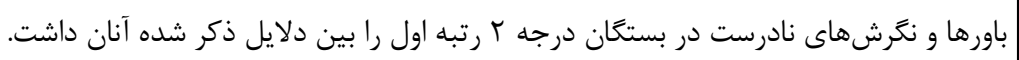
نتيجهَيرى: از بستكان زنان مبتلا به سرطان پستان، با توجه به احتمال بالاى ابتلا به اين سرطان،

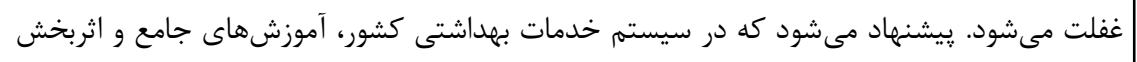

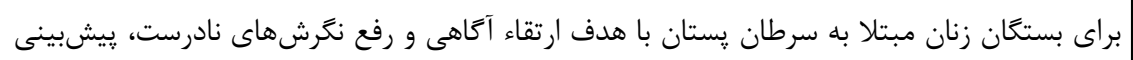
شود.
تاريخ ارسال:

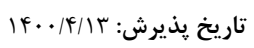

"نويسنده مسئول: n_keshavars@yahoo.com 
جوانى مواجه مىشوند (1، له) و در بسيارى از موارد، مقدمه

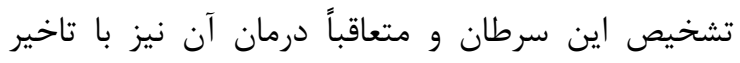

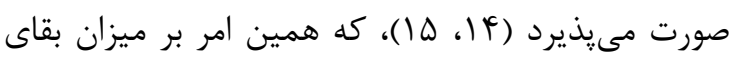

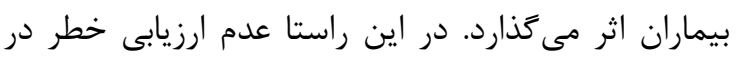

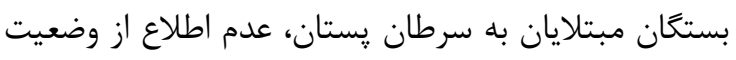

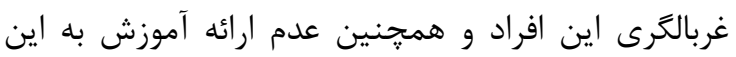

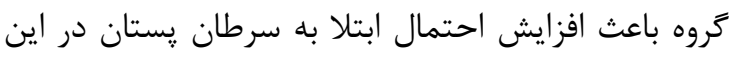

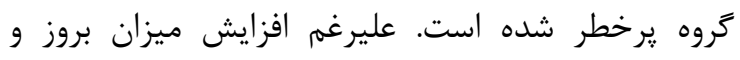

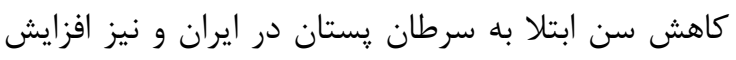

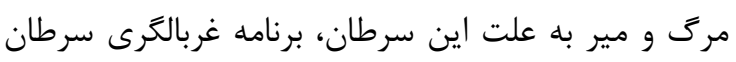

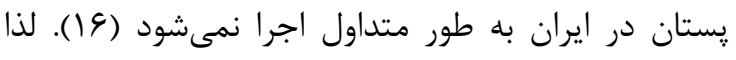

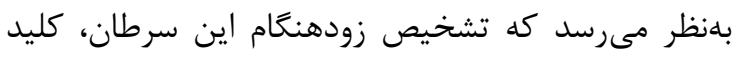
كاهش بار اين بيمارى باشد (هارس، (IV)

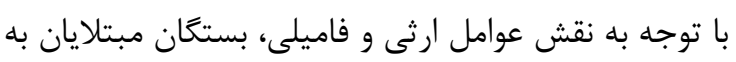

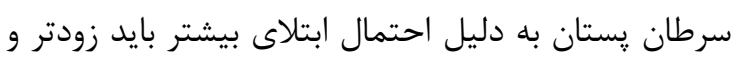
سريعتر تحت ارزيابى و تشخيص اين بيمارى قرار كيرند

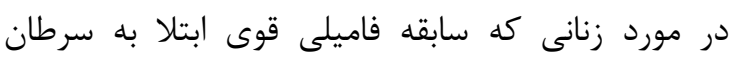

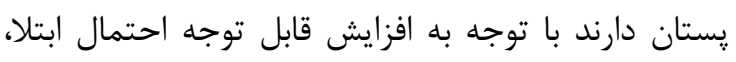

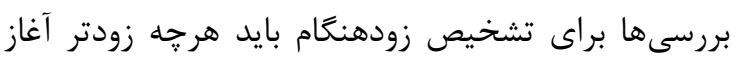

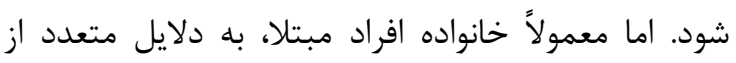

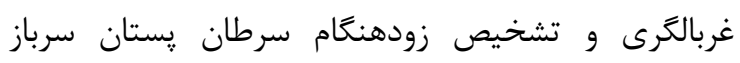

مىزنند (1) (1).

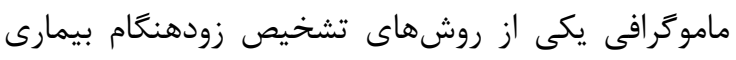

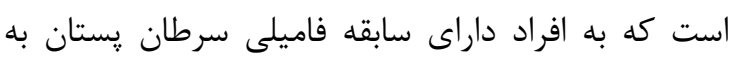
خصوص افراد يرخطر توصيه مىشود (9 (1). ميزان انجام

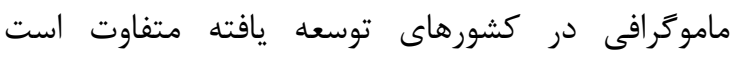

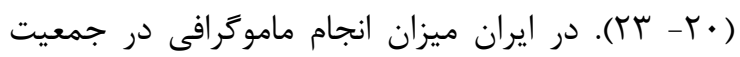

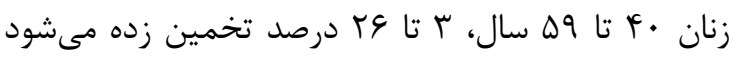
هY)

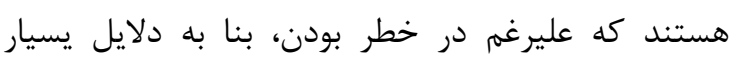

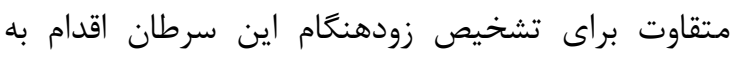

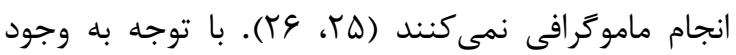

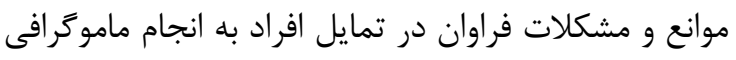

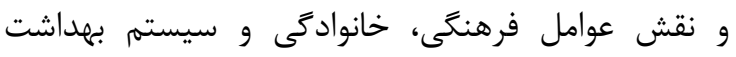

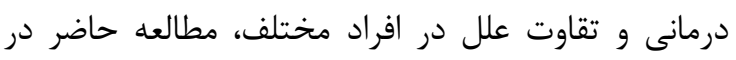

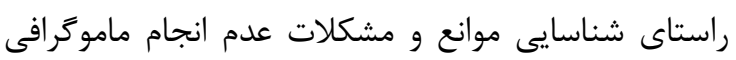

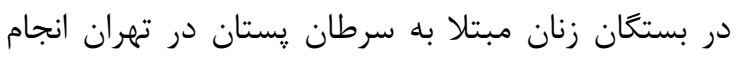

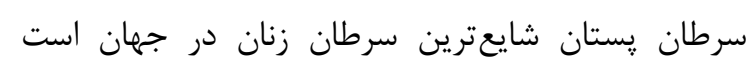

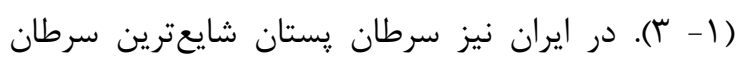

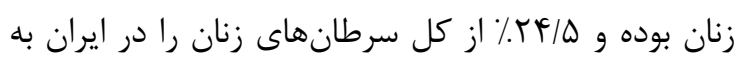

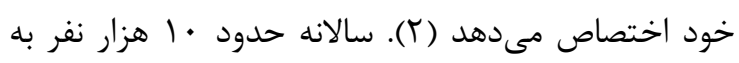

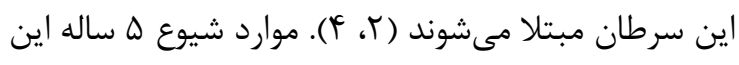

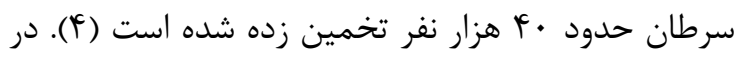

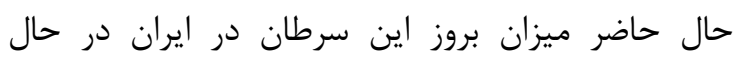

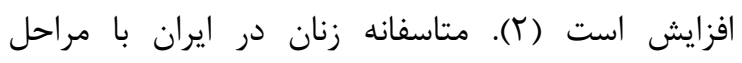
״يشرفتهترى از سرطان يستان در سنين جوانى مواجه مىشوند (1، له).

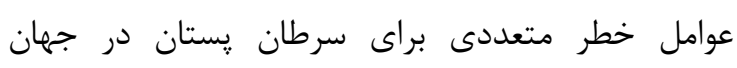

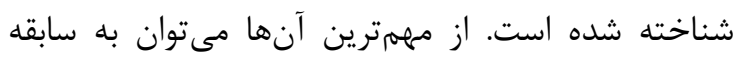

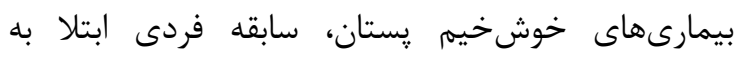

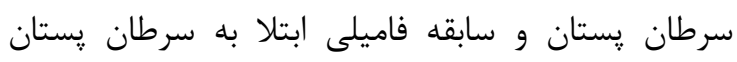

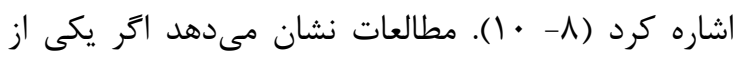

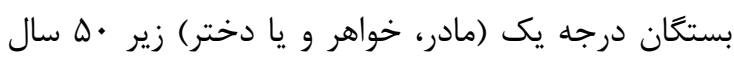

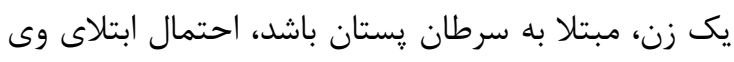

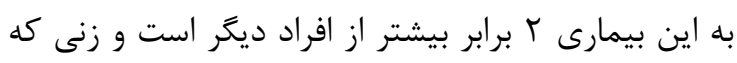

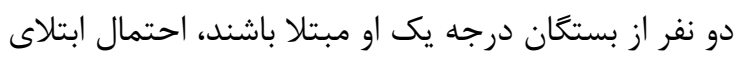

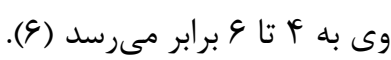

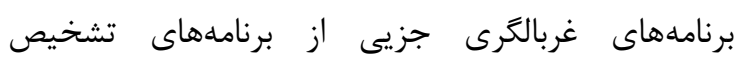

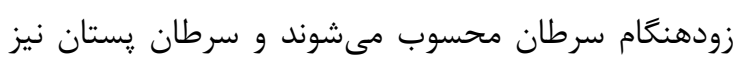

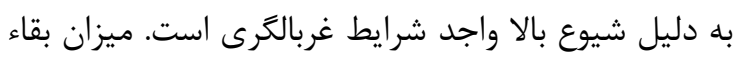

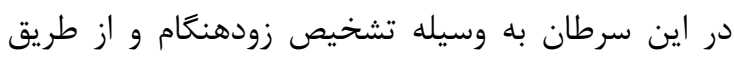

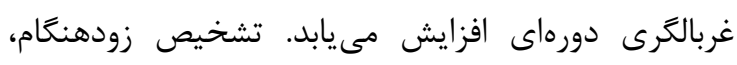

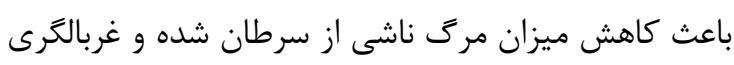

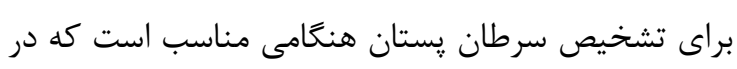

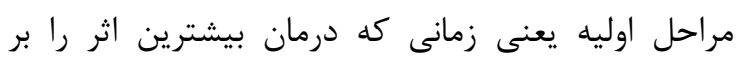

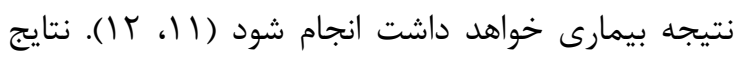

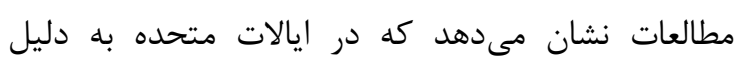

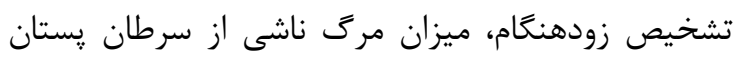

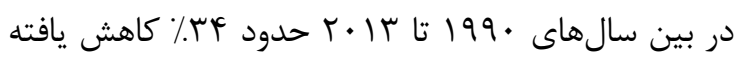

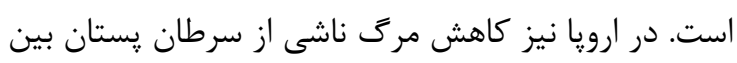

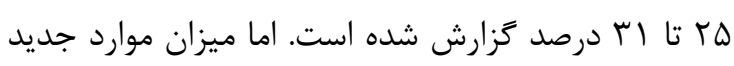

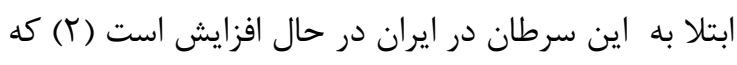

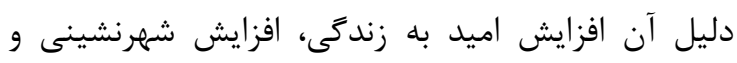

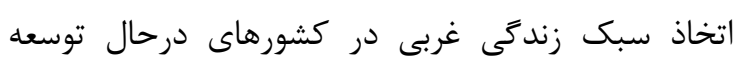

مانند ايران است (بان (1).

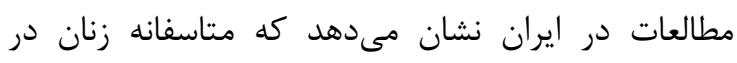

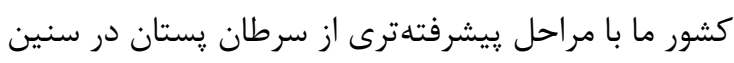


مصاحبهها معمولا تا دستيابى به دادهاى عميق ادامه

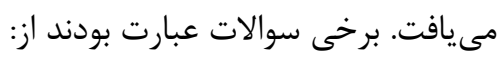

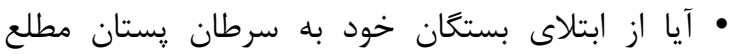

هستيد؟

• آيا تاكنون اقدامى براى شناسايى و تشخيص سرطان

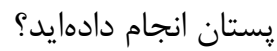

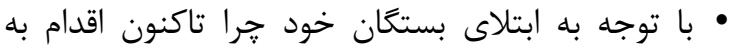

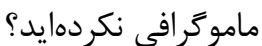

با اجازه و اطلاع قبلى مصاحبه شوندكان تمردامى فيد مصاحبهها

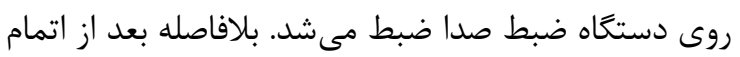

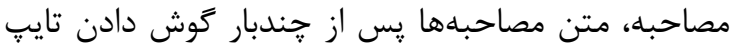

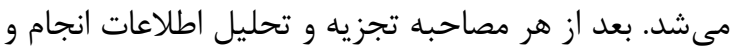

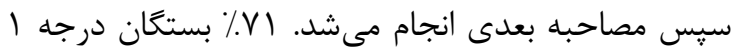

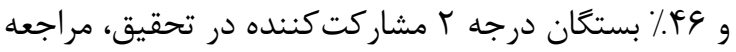
حضورى داشته و بقيه بستگان با تماس تلفنى مصاحبه

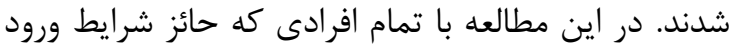

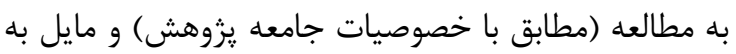

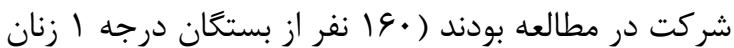

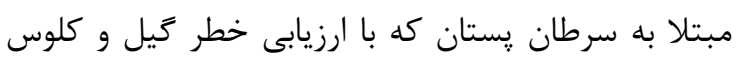

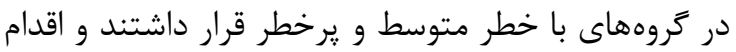

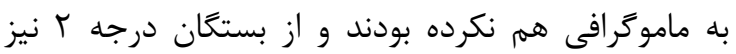

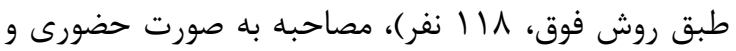

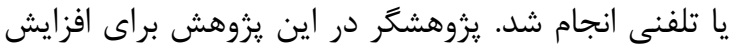

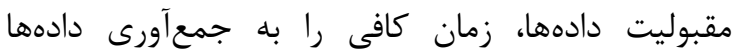
تخصيص داده و به جمعآورى و تحليل همزمان دادئ دادها

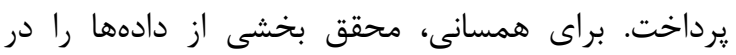

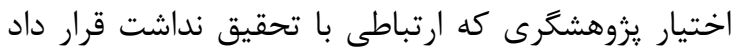

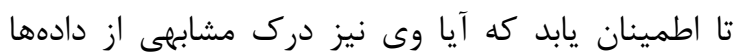

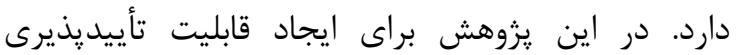

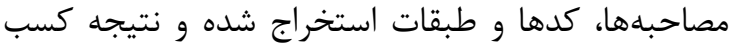
شده توسط دو نفر از اساتيد با تجربه در زمينه تحقيق

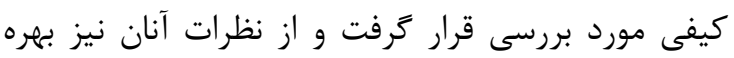

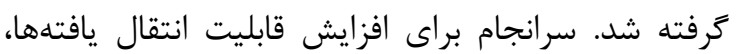

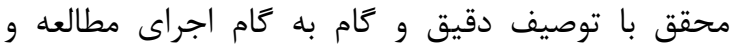
ويزگى هاى جمعيت مورد مطالعه، زمان و و مكان انجان انجام يزوهش، امكان استفاده از نتايج در محيطها و موقعيتهاى وداى

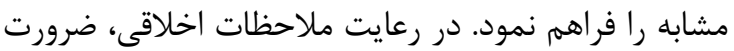

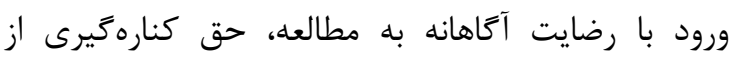

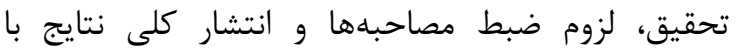

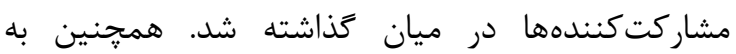
شركتكنندكان اطمينان داده شد كه در صورت تمايل،
يزوهش حاضر يك مطالعه كيفى از نوع بديدارشناسى

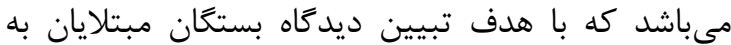

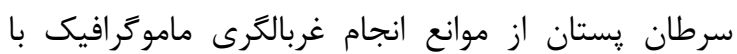
روش مصاحبه عميق نيمه ساختاريافته انجام يافت. اين إنان

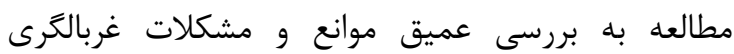

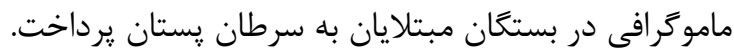

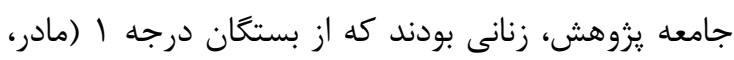

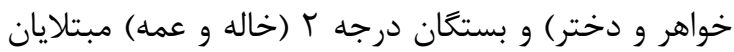

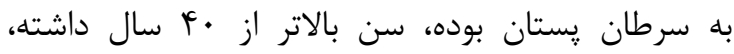

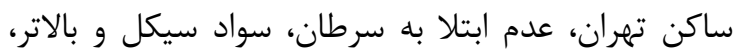

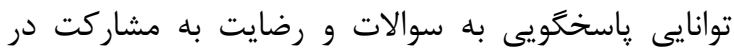

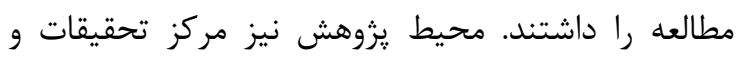

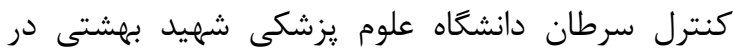

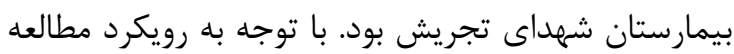
كيفى، روش نمونه

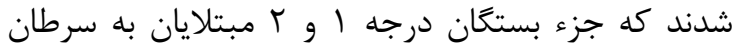

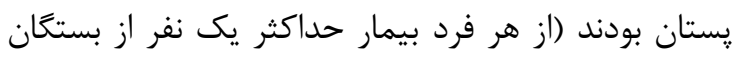

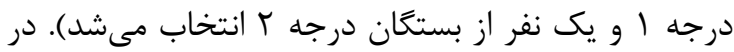

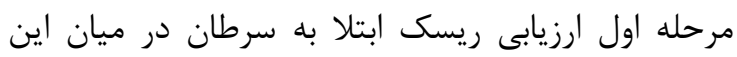
زنان بر اساس ابزار ارزيابى خطر كيل و كلوس انجام شد.

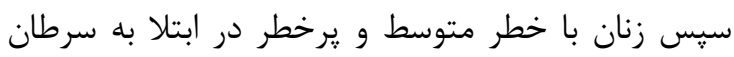

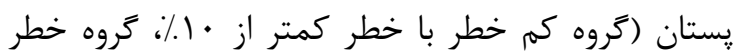

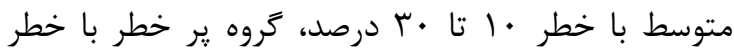

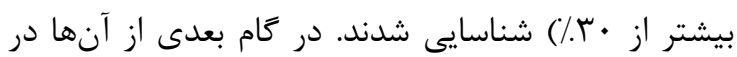
مورد سابقه انجام ماموكرافى سوال شد و و كسانى كانى كه

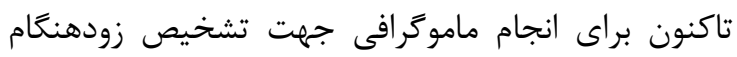

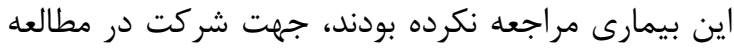

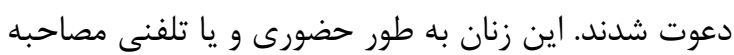
شدند تا به دلايل عدم انجام ماموَّرافى توسط آنان بان با توجه

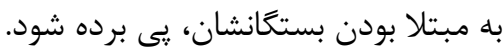

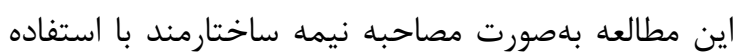

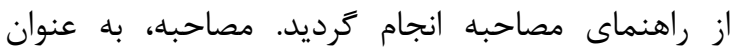

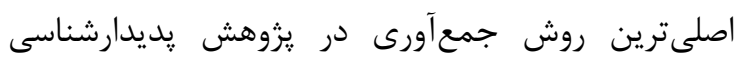

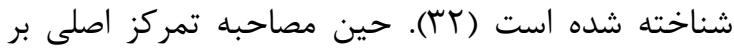

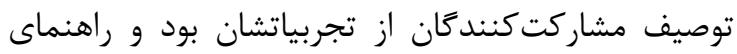

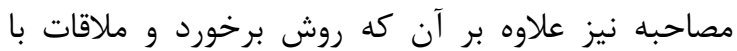

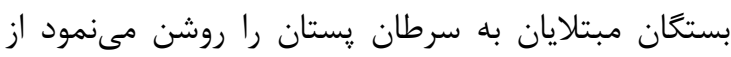

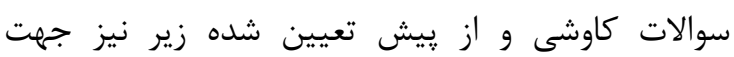

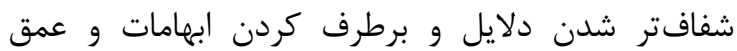

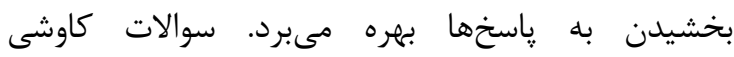


شود و سرانجام در تحليل تفسيرى، يزوهشكر در صدد آن

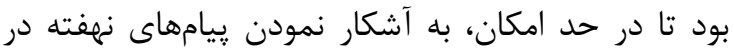

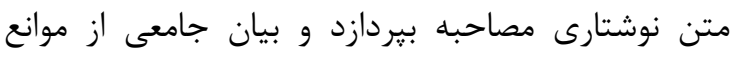

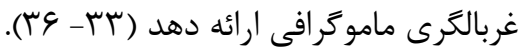

\section{كافتههـا}

در بستكان درجه ا اكثريت مشاركتكنيدان خوان خواهران

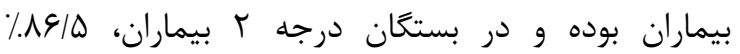

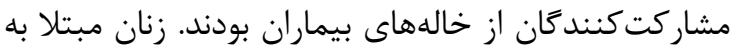

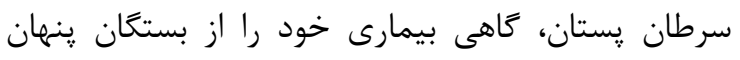

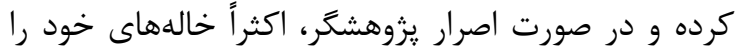

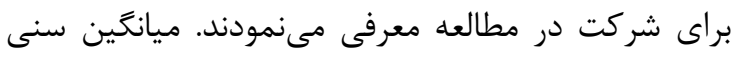

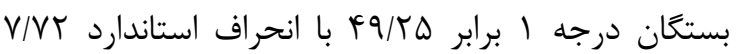

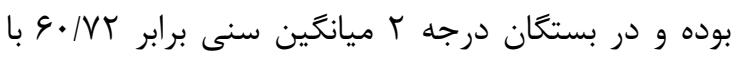

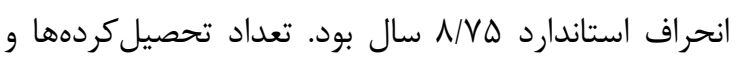

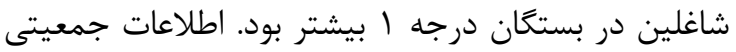

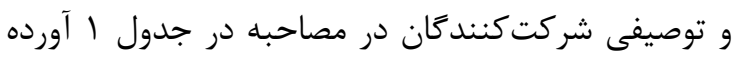
شده است.
اطلاعات ضبط شده و متن مصاحبههاى تايب شده در اختيار آنها قرار داده خواهد شد. اين يزوهش دان در كميته

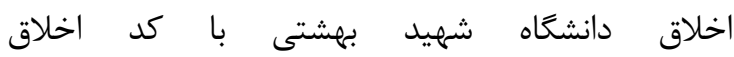
IR.SBMU.PHNS.REC.1395 به ثبت رسيده است. از آنجا كه در مطالعه حاضر، تاكيد بر سازماندهى و توصيف عميق دادها و درك مفاهيم بيدا و نايِيداى تعابير بود لذا

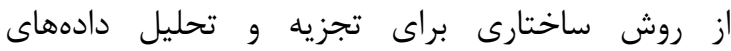

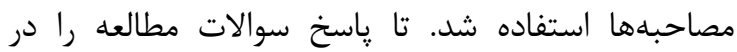

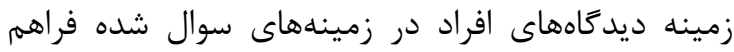

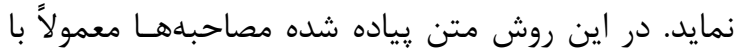
سه روش كمى، ساختارى و تفسيرى تجزيه و تحليل شد.

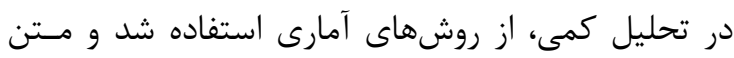

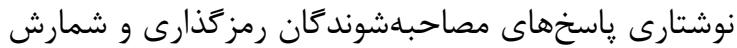

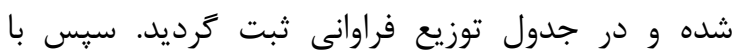
آزمونهاى آمارى مانند درصدهاى توزيع، فراوانى و درو درصد

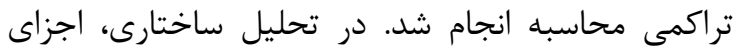

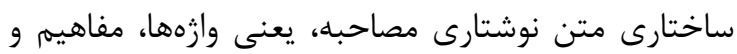

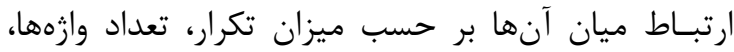

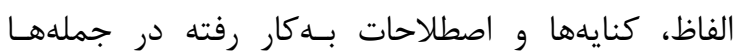

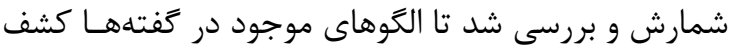

جدول ا: اطلاعات جمعيتى و توصيفى شركت كنندگًان در مصاحبه

\begin{tabular}{|c|c|c|c|c|c|}
\hline درجد & فراوانى & درجد & فراوانى & تروهها & متغير \\
\hline- & - & $\varepsilon \wedge / \cdot$ & ع & خواهر & \multirow{3}{*}{ نسبت با بيمار (درجه () } \\
\hline- & - & $\mid r / \cdot$ & rq & دختر & \\
\hline- & - & $19 / \cdot$ & rی & مادر & \\
\hline$\Lambda \& / \Delta$ & IVT & - & - & خاله & \multirow{2}{*}{ نسبت با بيمار (درجه ץ) } \\
\hline $1 \pi / \Delta$ & TV & - & - & عمل & \\
\hline १/• & 11 & $\Delta \Lambda / \Delta$ & $11 \mathrm{~V}$ & $p \cdot-r q$ & \multirow{3}{*}{ سن } \\
\hline$r F / D$ & 99 & $r q / \cdot$ & $\Delta \Lambda$ & $\Delta \cdot-\Delta q$ & \\
\hline$\Delta \& / \Delta$ & 114 & $1 T / \Delta$ & $r \Delta$ & بيشتر يا مساوى .4 & \\
\hline$\vee 9 / \Delta$ & 109 & $\mid \psi_{1 / \cdot}$ & Ar & سيكل & \multirow{4}{*}{ تحصيلات } \\
\hline $191 \cdot$ & rt & $r \Delta / \Delta$ & Q1 & دييلهم & \\
\hline$r / \cdot$ & 9 & rq/. & $\Delta \Lambda$ & ل ل ليسانس & \\
\hline $1 / 0$ & r & $F / \Delta$ & 9 & فوق ليسانس/دكترا & \\
\hline$\Lambda r / \cdot$ & lat & $\Delta \& / \Delta$ & $11 \pi$ & خانهدار & \multirow{2}{*}{ 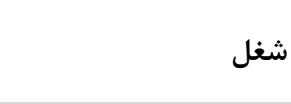 } \\
\hline $1 \mathrm{~N} / \cdot$ & re & 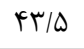 & $\wedge \vee$ & شاغل & \\
\hline $99 / \cdot$ & Irk & $\Lambda r / \Delta$ & 190 & متاهل & \multirow{4}{*}{ وضعيت تاهل } \\
\hline$r / \cdot$ & r & $\mathrm{V} / \cdot$ & If & مجرد & \\
\hline$r T / \cdot$ & fF & $\Delta / \cdot$ & $1 \cdot$ & بيوه بيو & \\
\hline $\mathrm{V} / \cdot$ & 14 & $\Delta / \Delta$ & 11 & مطلقه & \\
\hline
\end{tabular}


يا درمان نكردنش فرق زيادى ندارد. به عنوان مثال يكى از

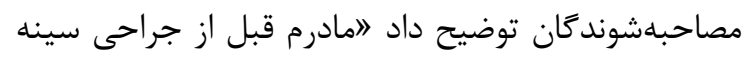

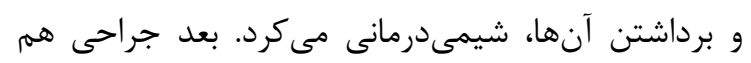

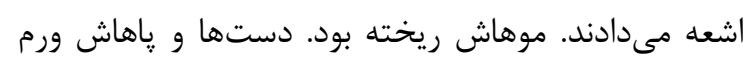

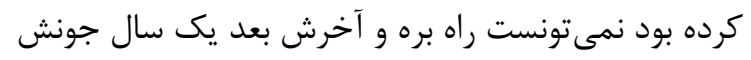

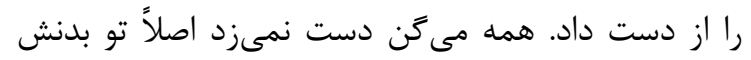
تخش نمىشده (مصاحبه شماره

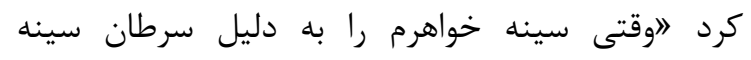

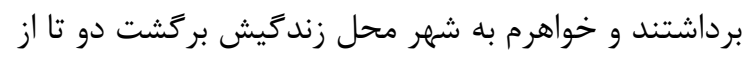

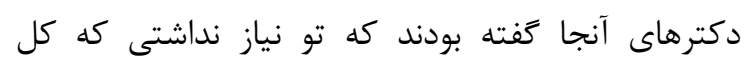

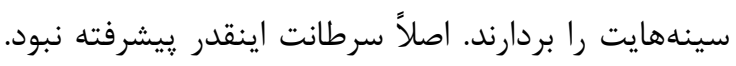
منم از جراحى و درمانهاى اشتباه مىترسمه (مصاحبه

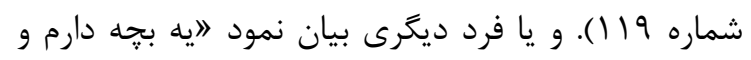

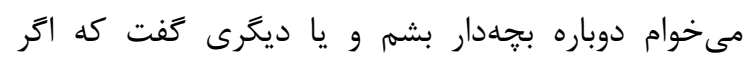

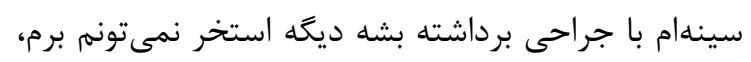

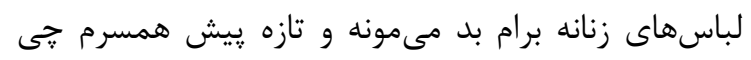
كار كنمه (مصاحبه شماره • له).

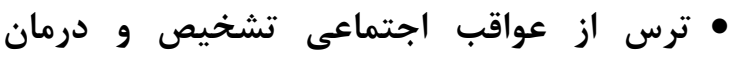
سرطان

به غير از عوارض تشخيص و درمان براى خود فرد، برخى به عوارض اجتماعى تشخيص سرطان سينه اشاره نمودند.

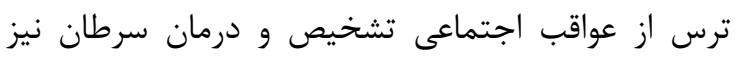

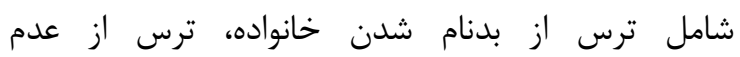

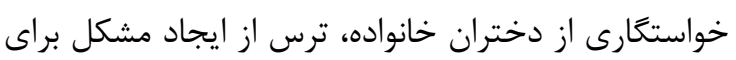

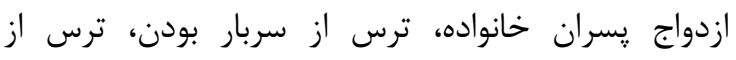

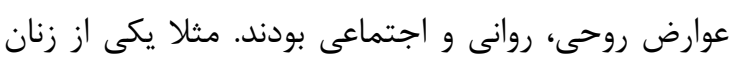

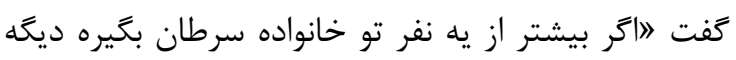

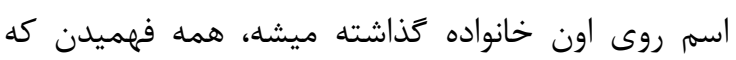

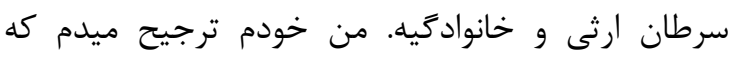
دنبال سرطان نباشم تا اخر ثابت بشه ديخه دختر

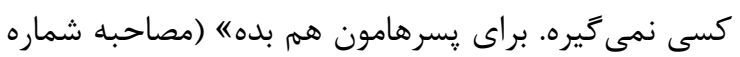

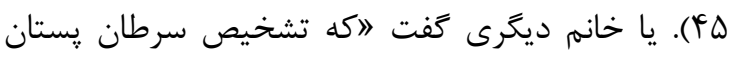

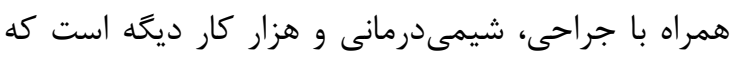

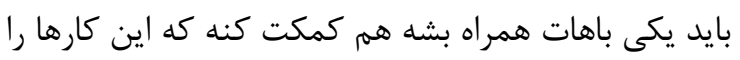

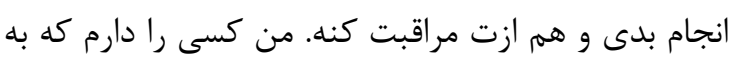

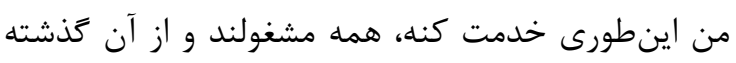
من دوست ندارم سربار كسى باشمه (مصاحبه شماره هـ أF). زنان ديكرى هم دليل عدم انجام ماموكرافى را را مسايل

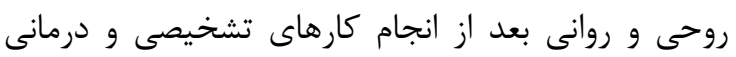
مطرح مى كردند.
تحليل يافتهها دلايل متعددى (دليل VY) را توسط بستكان

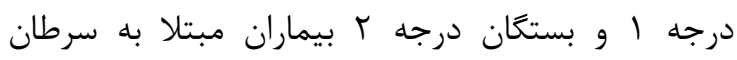

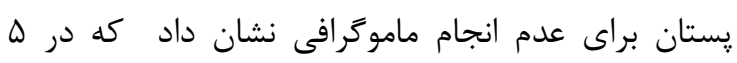

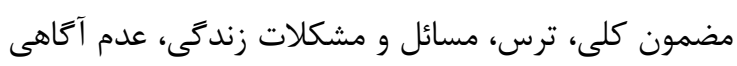

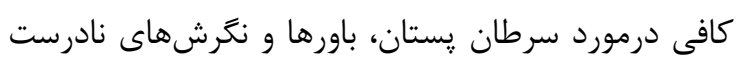

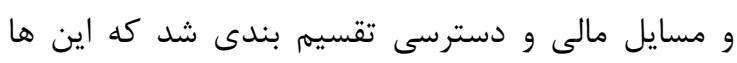

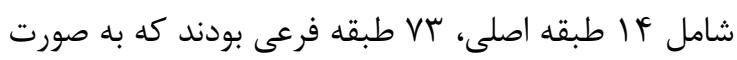

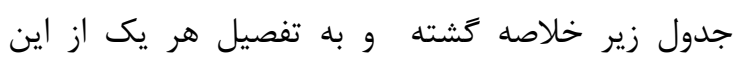

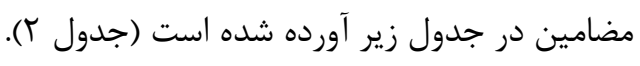
ترس ترس يكى از دلايل مهمم بيان شده توسط زنان بود كه خود

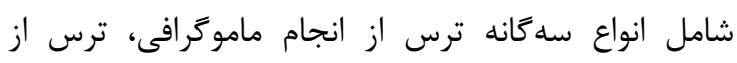

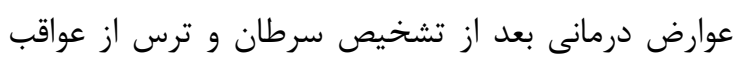

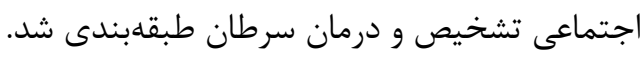

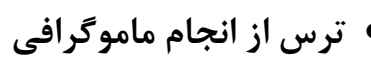

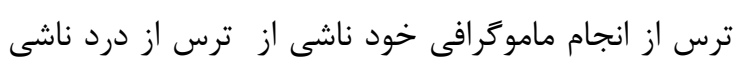

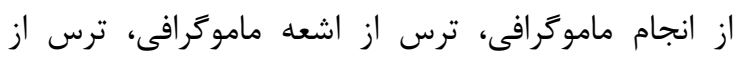

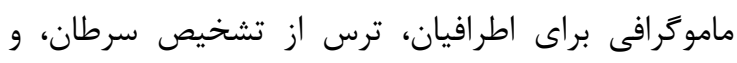

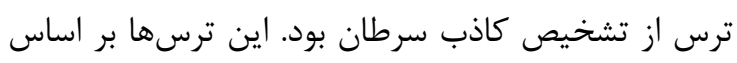

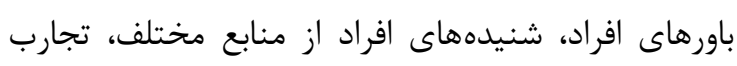

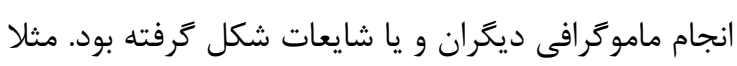

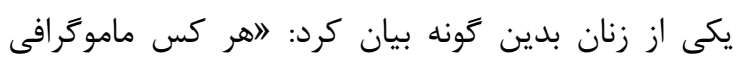

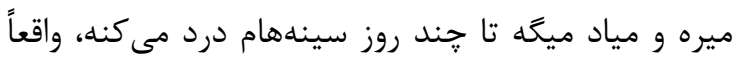

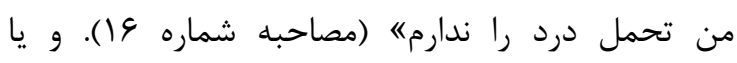

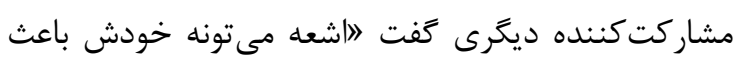

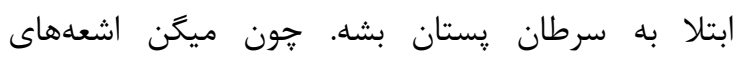
ماموكرافى سينه سالم را هم مىسوزونهان بنه (مصاحبه شماره

() (1)

\section{• ترس از عوارض درمانى بعد از تشخيص سرطان}

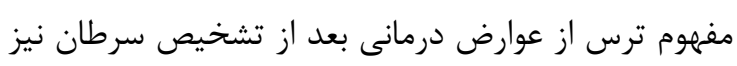

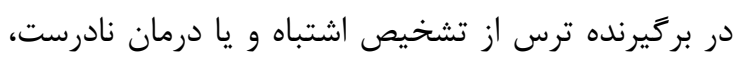

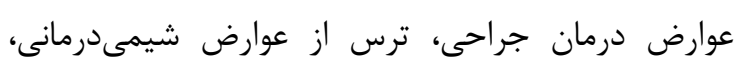

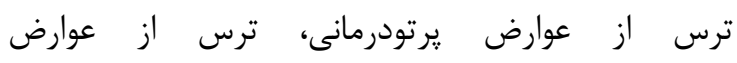

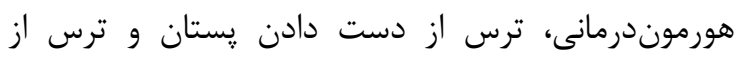

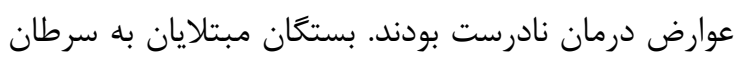

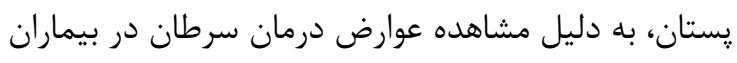

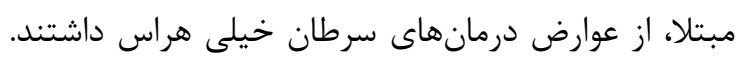
برخى از مصاحبه شوندكان معتقد بودند ماموكرافى حتى حتى إنى

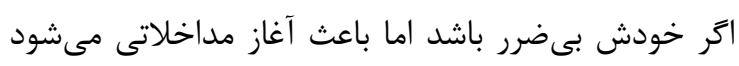

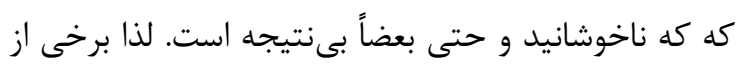

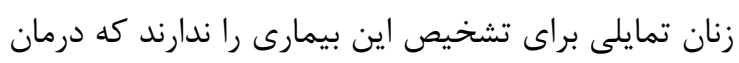




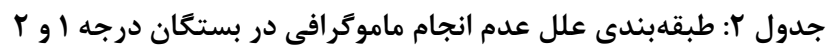
طبقه فرعى ند

طبقه اصلى

ترس از درد ناشى از انجام ماموكر افى لقى

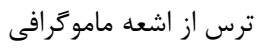

ترس از ضرر ماموكرافى براى اطرافيان

ترس از انجام ماموكرافى

ترس از تشخيص سرطان

ترس از تشخيص كاذب سرطان

ترس از عوارض درمان جراحى نق

ترس از عوارض شيمى درمانى

ترس از عوارض يرتودرمانى

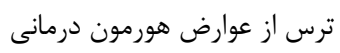

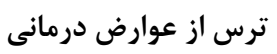

بعد از تشخيص سرطان

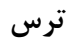

ترس از دست دادن سينه

ترس از درمان نادرست

ترس از بد نام شدن خانواده

ترس از عدم خواستگارى از دختران خانواده

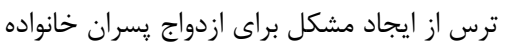

ترس از سربار بودن

ترس از عواقب اجتماعى

تشخيص و درمان سرطان

ترس از عوارض روحى، روانى و اجتماعى

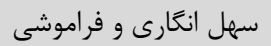

بى توجهى به سلامتى

دركير بيمارىهاى ديخر بودن بونئ

فردى

كار و مشغوليت زياد

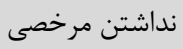

مخالفت همسر

اعتياد

مسائل و مشكلات زندكى

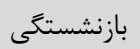

خانهنشينى و بيكارى

بيمارى

خانوادگى

داشتن فرزند خردسال

داشتن فرزندان زياد

داشتن فرزند معلول و بيمار

ندانستن، عدم سواد كافى و عدم مطالعه ورنه

عدم اطلاع از اهميت انجام ماموكرافى ندي

عدم اطلاعات و دانش

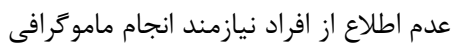

كافى در مورد شرايط و

عدم اطلاع از خطر ابتلاء به سرطان بستان در خود

موارد لزوم ماموكر افى

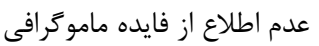

عدم آكاهى كافى در مورد

عدم اطلاع از روش انجام ماموكرافى

سرطان يستان

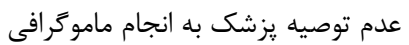

عدم توصيه كاركنان بهداشتى به انجام ماموكرافى يرى

عدم توصيه خانواده

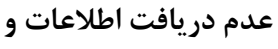

عدم توصيه دوستان

توصيه از ديكران 


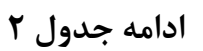

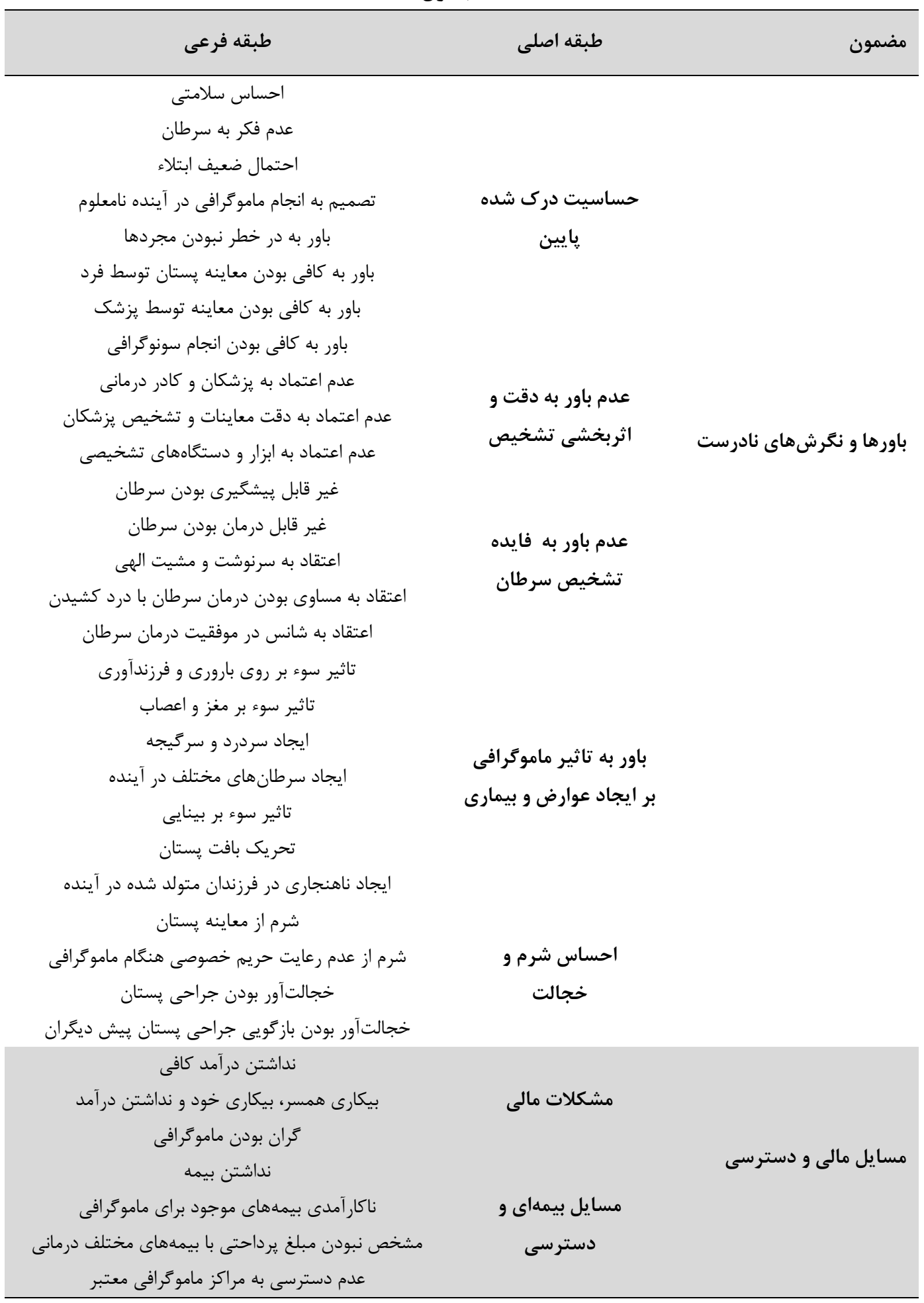

\section{مسائل و مشكلات زندكى}

مسائل و مشكلات زندكى در دو طبقل مشكلات زندى اصلى فردى و

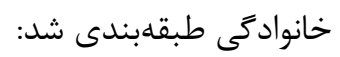

مثلا خانمى دليل عدم انجام ماموكرافى را اينكونه بيان

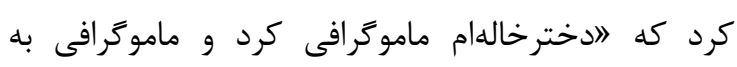

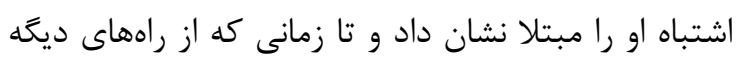
مطمئن بشه كه سرطان نداره، كلى استرس و نكخرانى كشيده (مصاحبه شماره 9؟). 
دانش كافى در مورد شرايط و موارد لزوم ماموكرافى و عدم دريافت اطلاعات و توصيه از ديكران دستهبندى شد:

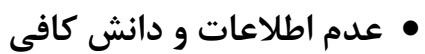

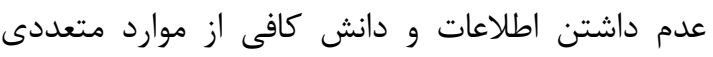

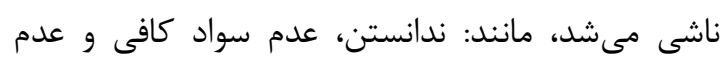
مطالعه، عدم اطلاع از اهميت انجام ماموكرافى، عدم إنى

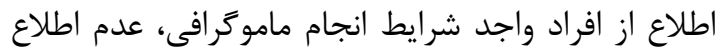

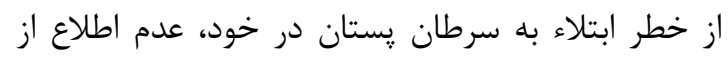

فايده ماموكرافى، عدم اطلاع از روش انجام ماموكر افى انى.

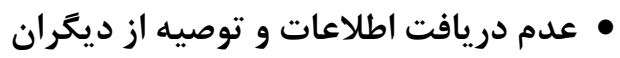

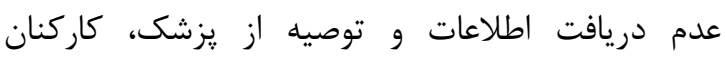

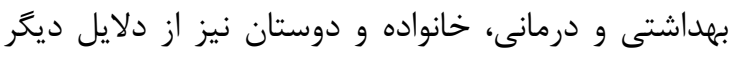

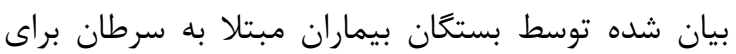

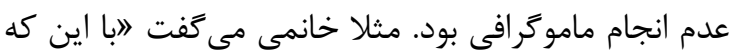

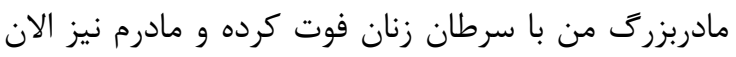

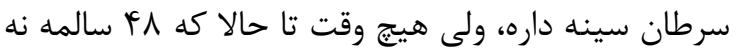

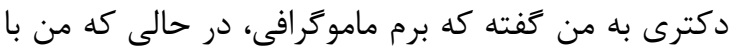

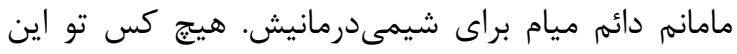

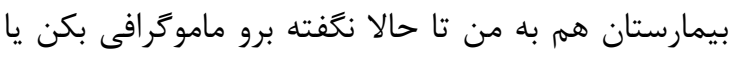

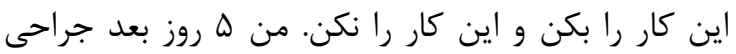
مامانم تو بيمارستان همراهش بودم حتى يرستارها هم به به

من نكفتن" (مصاحبه شماره سب).

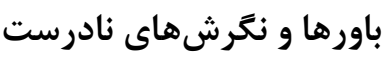

باورها يرتكرارترين دلايل عدم انجام ماموكرافى بودند. مضمون باورها و نكَرشاى نادرست نيز با طرح دلايلى از

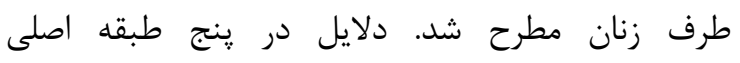
طبقهبندى شد:

• حساسيت درك شده پايين، كه در طبقات فرعى احساس سلامتى، عدم فكر به سرطان، احتمال ضعيف

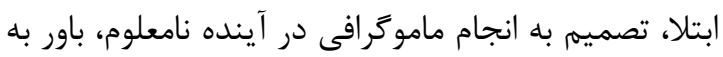
در خطر نبودن مجردها، باور به كافى بودن معاينه پرّتان

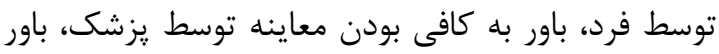

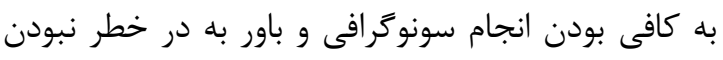

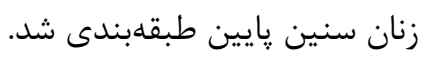

• عدم باور به دقت و اثربخشى تشخيص نيز به دانيل بلايل

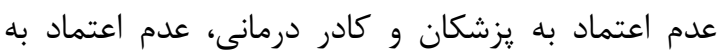

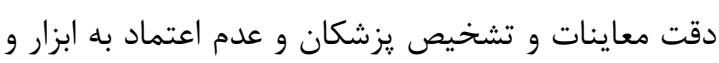
دستخاههاى تشخيصى مربوط بود. مثلا خانمى بيان نمود

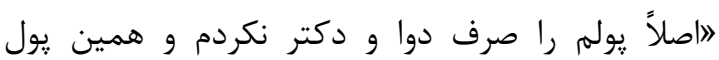

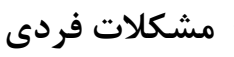

مشكلات فردى كه دليل عدم انجام ماموكرافى بيان شد مد مدات شامل طبقات فرعى از جمله سهل انكارى، باور نداشتن به فيه

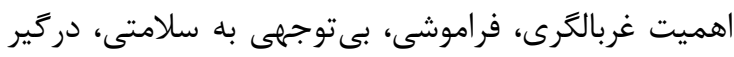

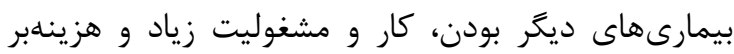

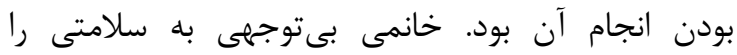

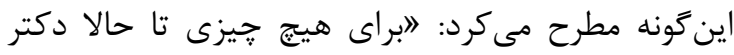

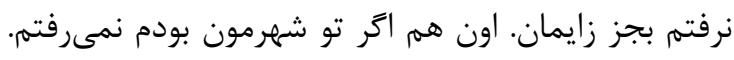

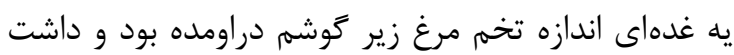
بزرى مى شد و من با روسرى مى يوشوندم. تا اين كه خود

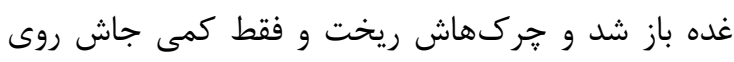

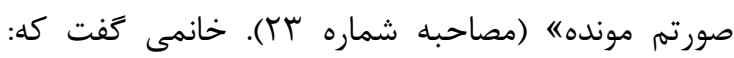

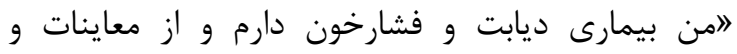

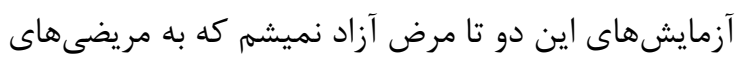

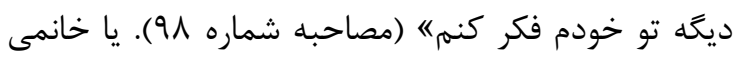

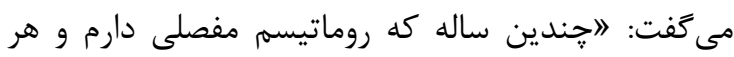

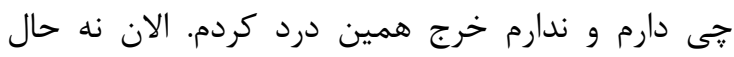

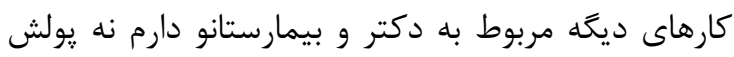
را《 (مصاحبه شماره

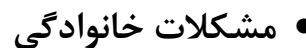

مشكلات خانوادگى بيان شده نيز شامل مخالفت همسران

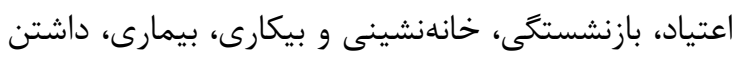

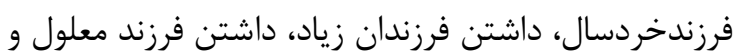

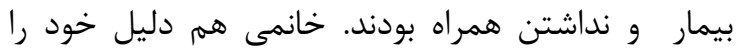

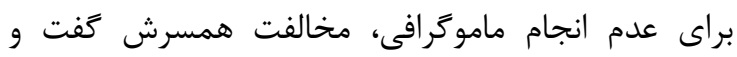

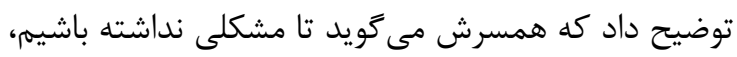
هزينه اين جور كارها را نمى دهد و اعتقادى به اين كارها

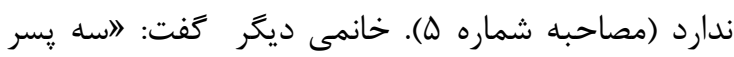

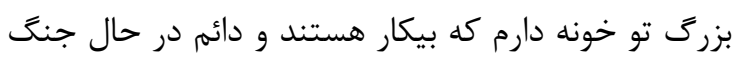
و دعوا. نمى تونم اونا را بذارم از خونه بيام بيرونه (مصاحبه ديه

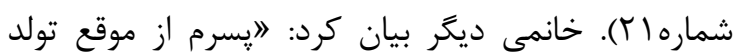

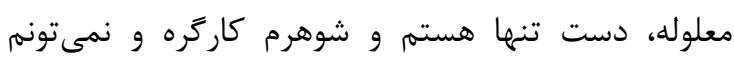
بحهم را تنها تو خونه بذارم و بيامه (مصاحبه شمارهضَّ). خانمى نيز دليل عدم انجام كارهاى تشخيصى از جمله

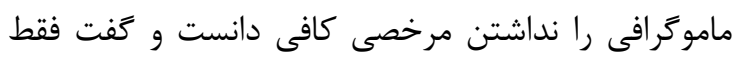

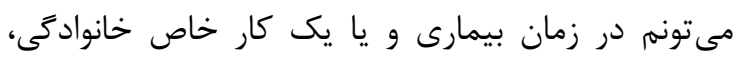
مرخصى داشته باشم (مصاحبه شماره فDان. عدم آتاهى در مورد سرطان يستان اين مضمون نيز در دو طبقه اصلى شامل عدم اطلاعات و ود سلنان 
مى كنند مرد هستند. تازه من داماد دارم اكر جراحى

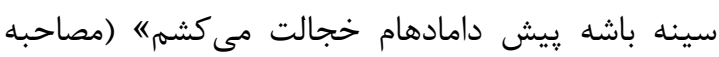

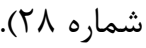
مسائل مالى و دسترسى

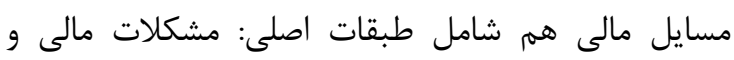
مسائل بيمهاى و دسترسى بود. مسائ.

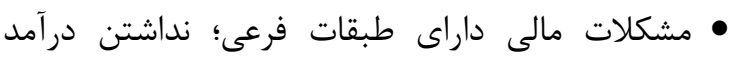

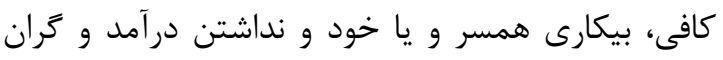

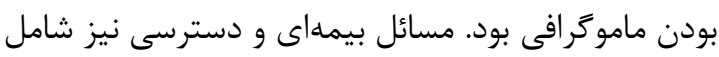

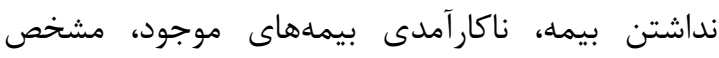

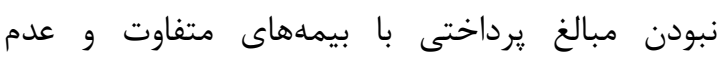
دسترسى و كافى نبودن مراكز معتبر ماموكرافى عنوان بيمهان

خانمى در مورد دلايل عدم انجام ماموكر افى خود بيان كرد

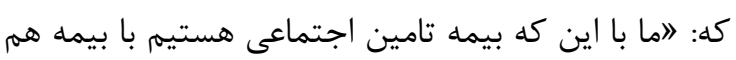

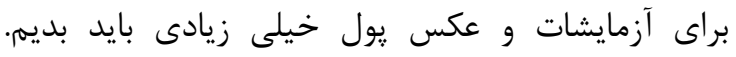

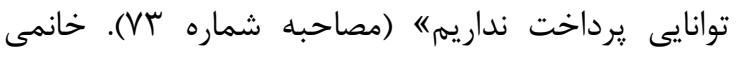

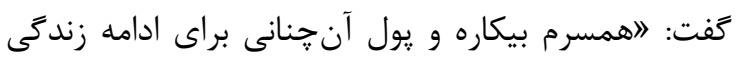

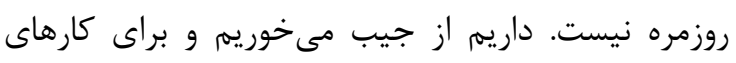

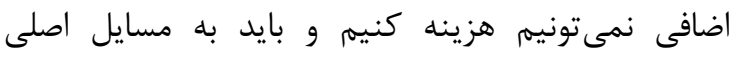

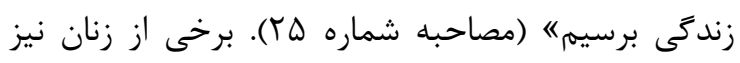

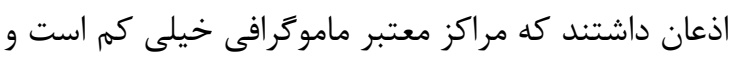

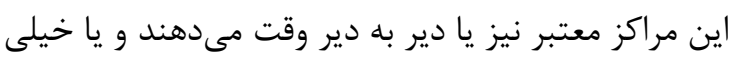

$$
\text { دور هستند. }
$$

بحث

در دهه اخير، مطالعات بسيارى در زمينه ارتقاء غربالكرى

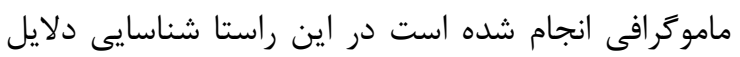

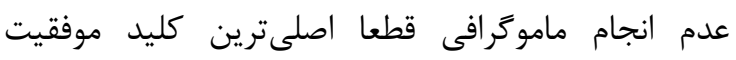
مداخلات ارتقا غربالكرى است.

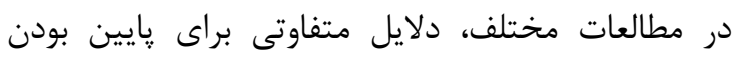

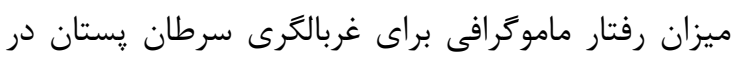

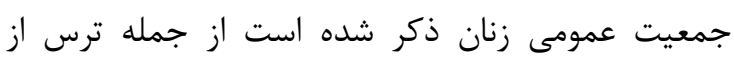
زيانبار بودن و دريافت اشعه حين ماموكرافى، نداشتن ذركان

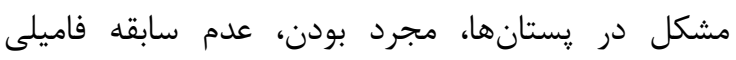

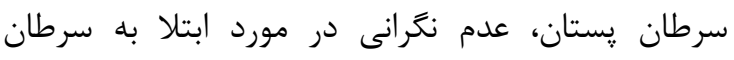
يستان، عدم اعتقاد به ضرورت انجام آن، نداشتن على علائم

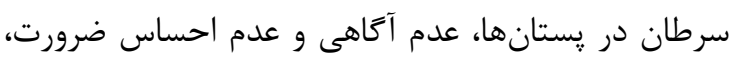

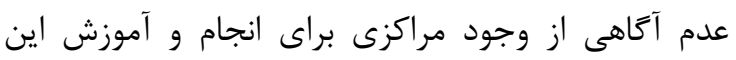

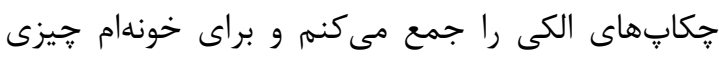

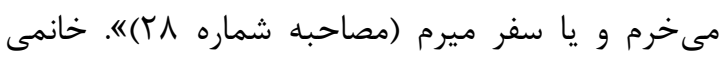

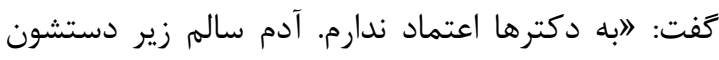

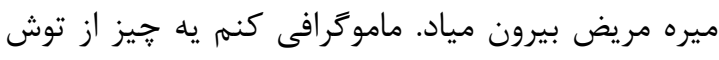

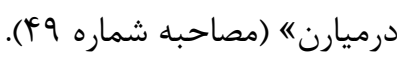
• عدم باور به فايده تشخيص سرطاح نمان هم در قالب طبقات

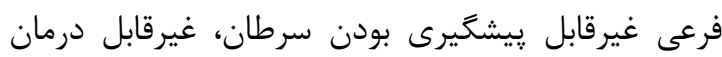
بودن سرطان، اعتقاد به سرنوشت و مشيت بريت الهيى، اعتقاد

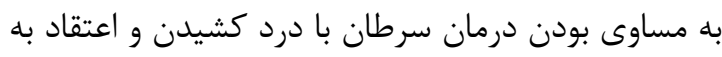

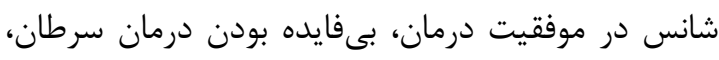

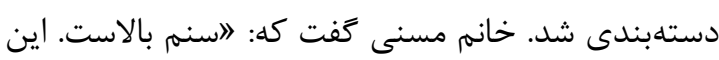

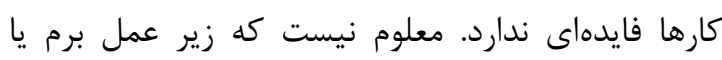

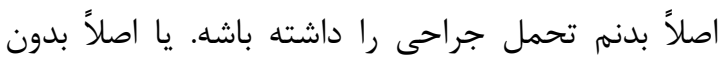

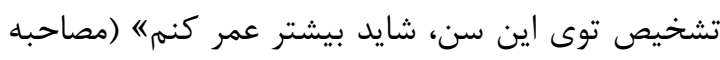

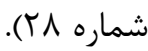
• باور به تاثير ماموگرافى بر ايجاد عوارض و بيمارى.

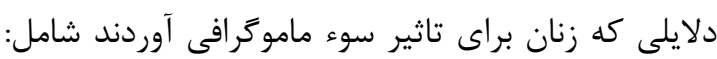
تاثير سوء بر روى بارورى و فرزندآورى، تاثير سوء بر ماني مغز

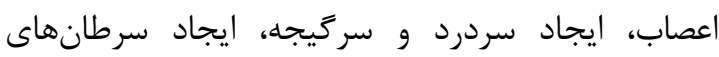

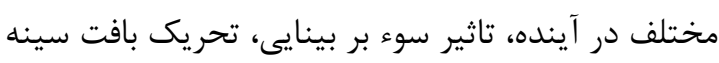

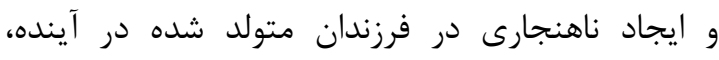

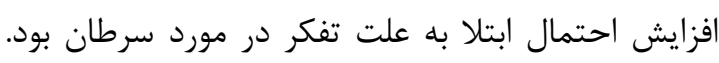

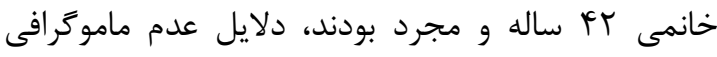

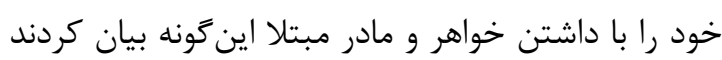

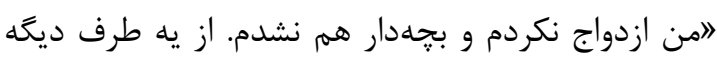

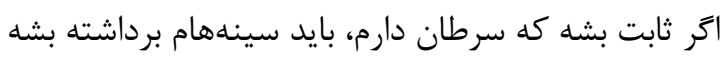

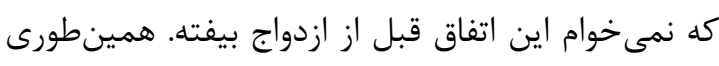

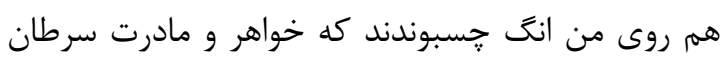
دارن تو هم مى خيرى. فكر مى كنهم يكى از دلائل

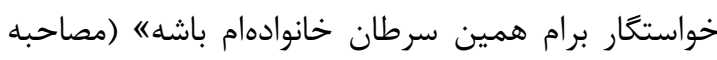

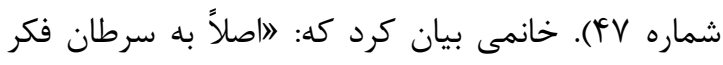

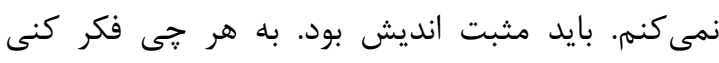

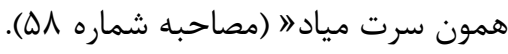

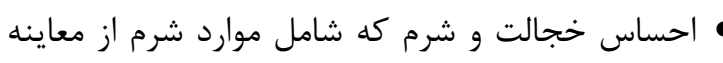

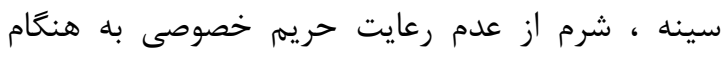

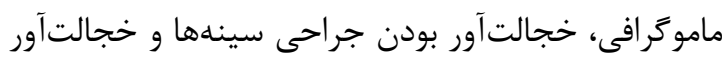

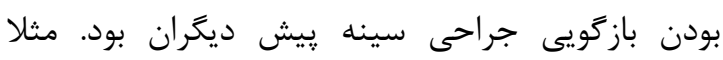

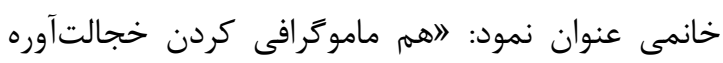

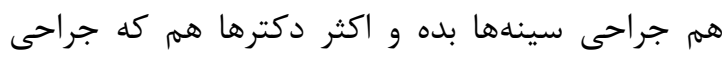


كردد. البته برخى مطالعات نيز به وجود فاصله بسيار بين دانش زنان و رفتار آنان در زمينه انجام ماموكرافى در ايران

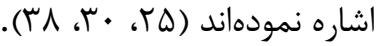

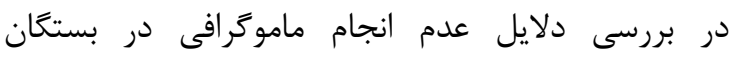
مبتلايان به سرطان يستان اولين مضمون اصلى ترس بودي در بررسى علت ترس بهنظر مىرسد كه ترس از سرطان،

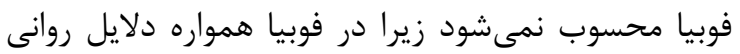
براى ايجاد ترس وجود دارد ولى ترس از سرطان يك ترس درس واقعى محسوب مىشود، زيرا بستكان افراد مبتلا به إنهان

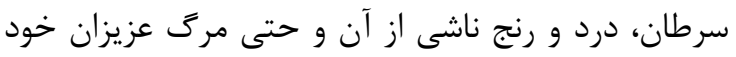
را به علت سرطان تجربه مى كنند. در اين مطالعه دلايل ترس در قالب سه محور اصلى شامل ترس از انجام ماموكرافى، ترس از عوارض درمانى بعد از تشخيص و ترس درس از عواقب اجتماعى تشخيص و درمان بيان شده است. بـ به إنه نظر مىرسد كه ترس از انجام ماموكرافى به احتمال زياد

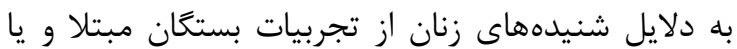

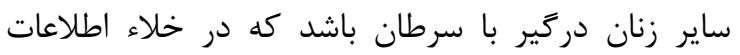
موثق روى رفتار آنان اثر تعيين كننده دارد. از طرف ديان ديكر دان داء زنان جه بسا اكاهانه از كشف حقيقت و تشخيص بيمارى اجتناب كنند، زيرا آنان را وارد راه ناشناختهاى همراه بان بان

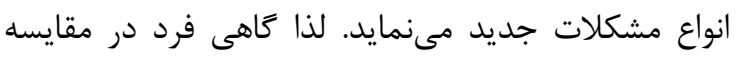

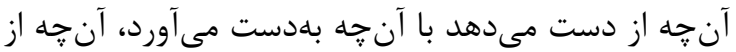
دست مىدهد را بيشتر و يا مهمتر از آنجه بهدست آنها

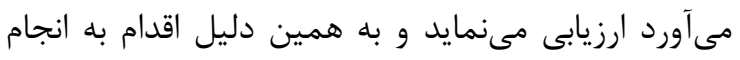

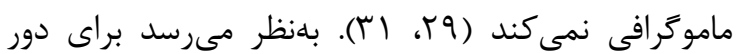
كردن ترس از سرطان در بستكان بيماران، بهتر است

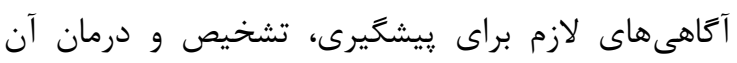

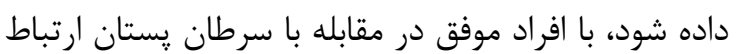

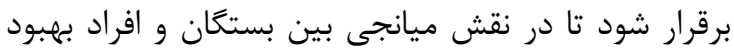

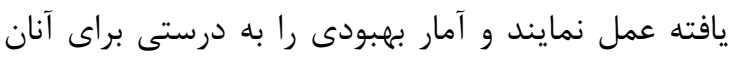

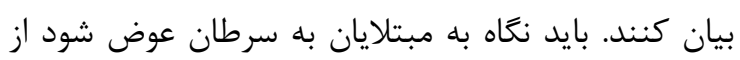

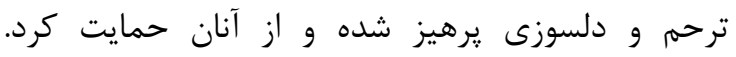
درضمن توجهات غيرضرورى نيز باعث ايجاد اين تصور

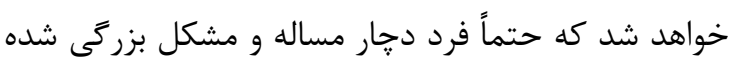

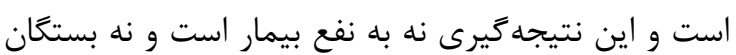
بيمار. از بستكان بيماران مبتلا به سرطان يستان بايد درخواست شود كه هر سوالى كه در ذهن خود در مورد

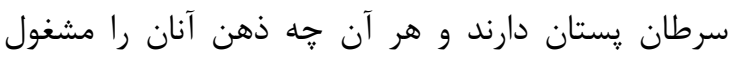

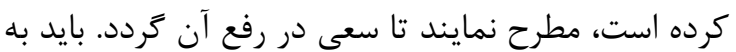

معاينات، ترس از سرطان، اعتقاد به سرنوشت، موانع ارتباط

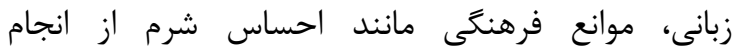

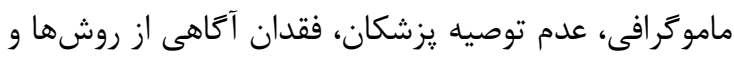

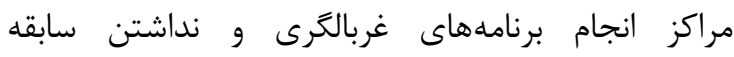

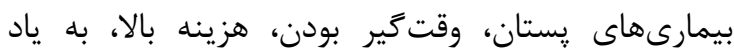
نداشتن انجام ماموكرافى و نكرانى در معرض اشعه قرار

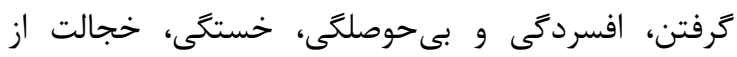
معاينات، ترس از معاينات و ترس از بيمار بودن، كيفيت خيتئ

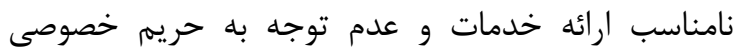
افراد، محدوديت اطلاعرسانى و دسترسى محدود زمانى و ورات

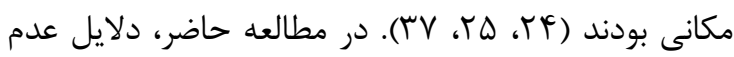
انجام ماموگرافى در بستكان مبتلايان به سرطان يستان كه در معرض خطر بيشترى نسبت به اين بيمارى هستند،

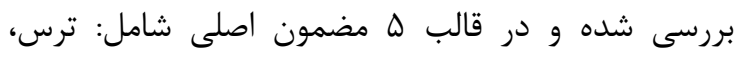

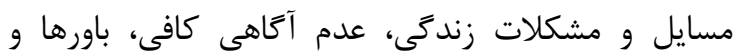
نخرشهاى نادرست، مسايل مالى و دسترسى به عنوان

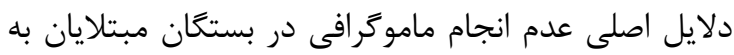

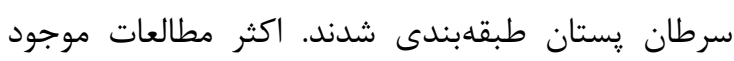
دلايل عدم انجام ماموكرافى را در جامعه عمومى زنان بررسى نمودهاند اما اين مطالعه به بر رسى دامي دلايل عدم انجام امعام

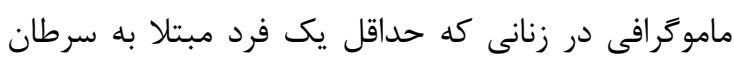

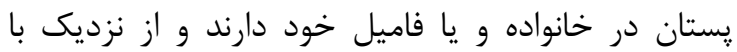
بيمارى مواجهه داشته و ميزان خطر بالايى نيز آنان ران إنان

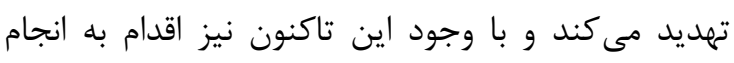
ماموكرافى نكردهاند، يرداخته است. توجه به به دلايل عدم إندام انجام ماموكرافى بايد در اولويت مداخلاتى كه قصد افزايش

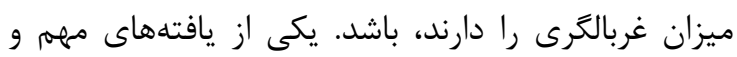

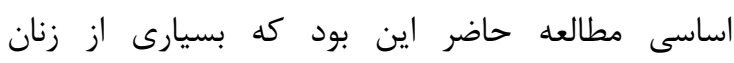
شركتكننده در مصاحبهها، اعلام نمودند كه با اطلاع از از إنان اين كه در معرض خطر بالاترى نسبت به جمعيت عمومى

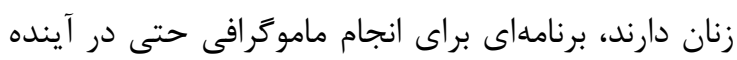

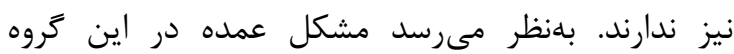
يرخطر عدم آتاهى و دانش كافى نباشد بلكه ساير ابعاد

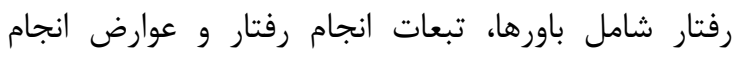
ماموكرافى نيز دخيل باشد. اين مساله نشان مى ندهد كهد

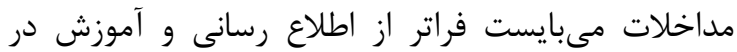

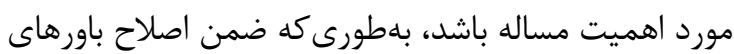

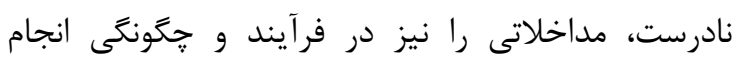

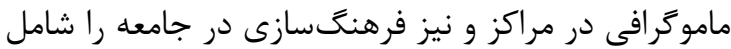


سرطان نيز بخواهند كه اعضاى خانواده خود را براى ترن تشخيص زودهنگام سرطان زبتان ترغيب كنند. مطالعات

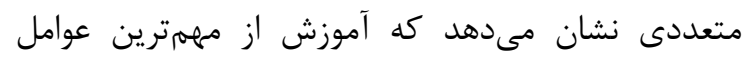

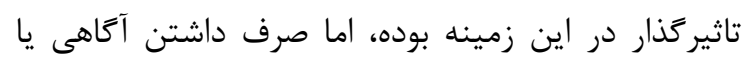

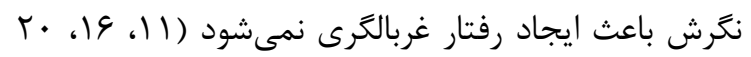

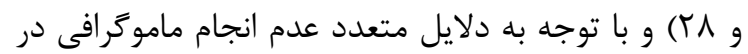
زنان يرخطر، فقط عدم آكاهى و نكَرش تعيين كنينده انجام

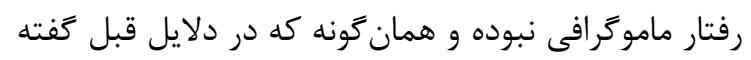

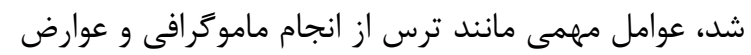
ناشى از آن، ترس از تشخيص سرطان و يا عوارض درمان

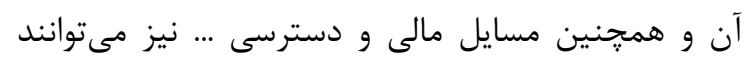
هلايل عدم انجام اين رفتار باشند كه قابل تعديل و اصلاح

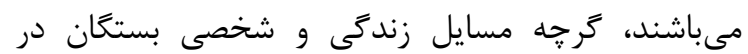
كنترل گروه بهداشتى و درمانى نيست اما، وظيفه كاركنان بهداشتى و درمانى در ارتقاى رفتارهاى غربالكرى بسيار

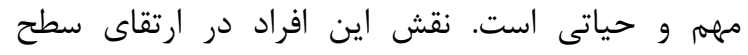
سلامت افراد جامعه و جلب مشاركت آنان دان در آنق مسايل

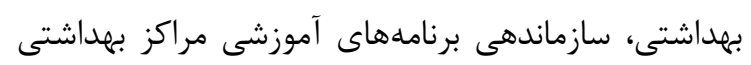

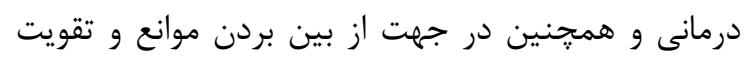

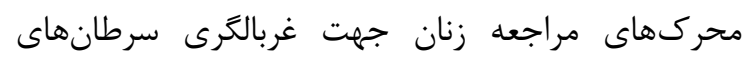

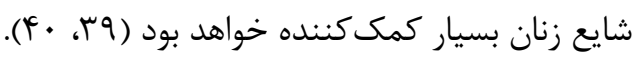

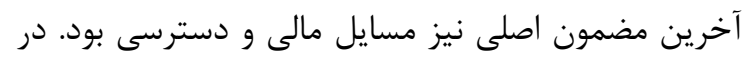
اين مورد دلايل عدم انجام ماموكرافى توسط بستكان

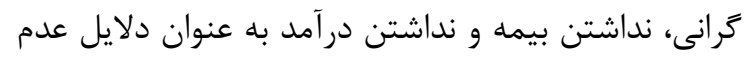

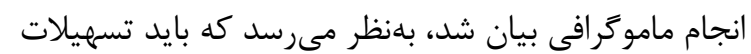
و تمهيدات خاصى براى بستكان مبتلايان به سرطان

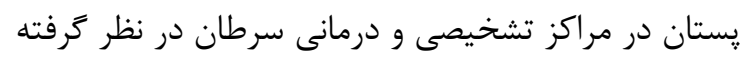

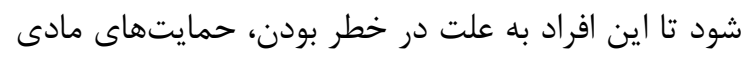
و معنوى و دسترسى مناسبترى به تشخيص زودهنغام

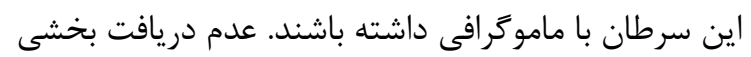

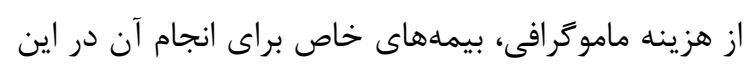

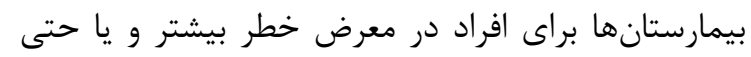

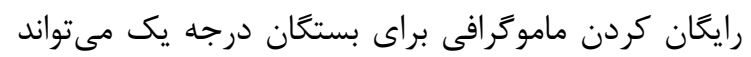
بخشى از تسهيلات و كمك هاى در نظر كرفته شده براي براى

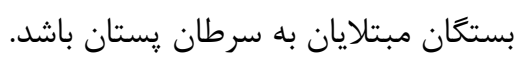

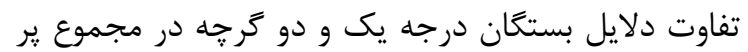

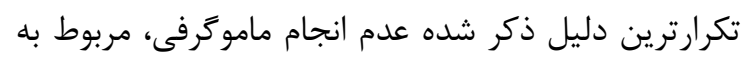

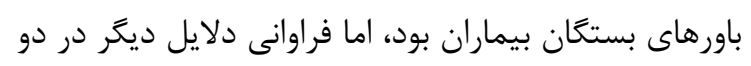
كروه بستگان درجه يك و دو با هم فرق داشت. در بستخان
آنان يادآورى نمود كه درست است كه سرطان يستان بيمارى سختى است اما با پيشرفتهاى ايجاد شده در دران

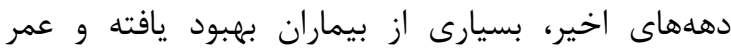

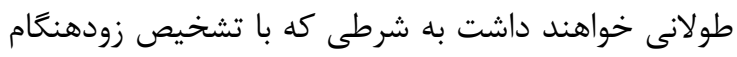

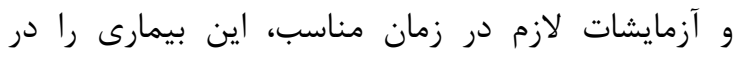
مراحل اوليه كشف و كنترل نمايند. البته كاهى مشاور ههاى روانشناسى نيز كمك كننده است.

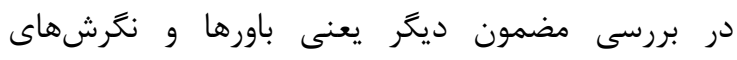

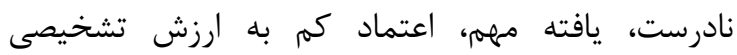

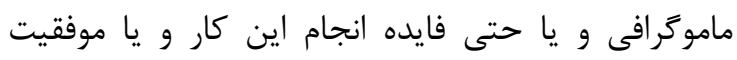

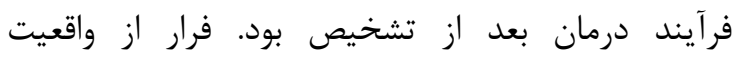

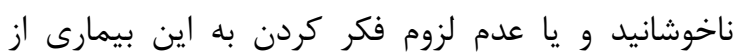

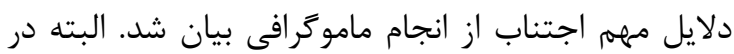

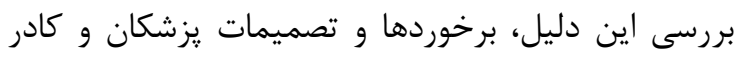

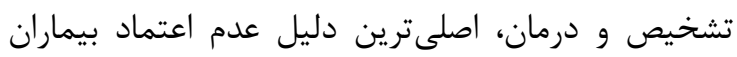
بود و بهنظر مىرسيد كه يزشكان و كادر تشخيص و درمان

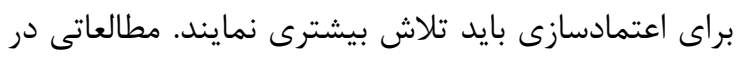

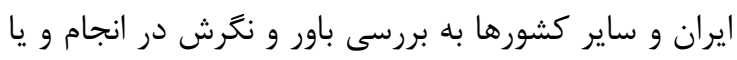

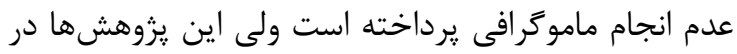

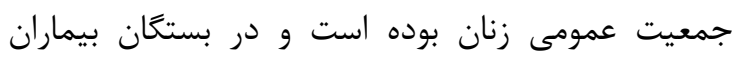

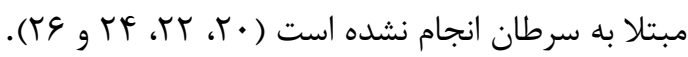
همجنين عدم رعايت حريم خصوصى توسط ساير عوامل تشخيص و درمان و نيز حضور كاركنان و دانشجويان در

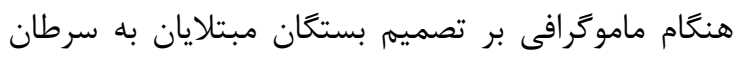

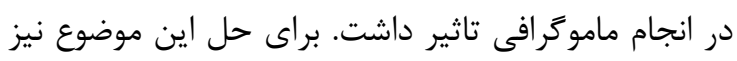

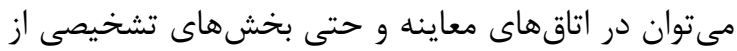
تجمع كاركنان و دانشجويان جلوَيرى نموده و و به حرئ حريم

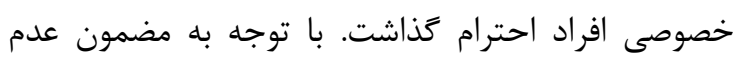
آكاهى در علل انجام ندادن ماموكرافى توسط بستخان نيز

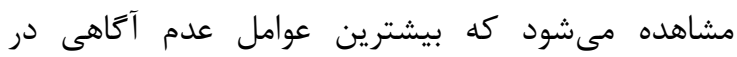

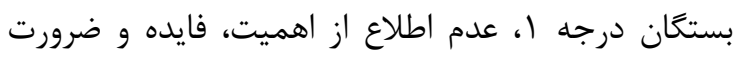

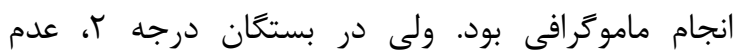

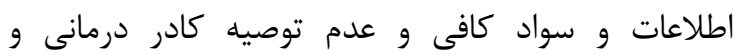

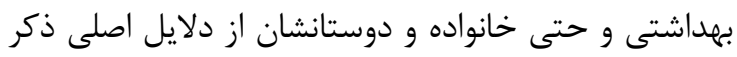

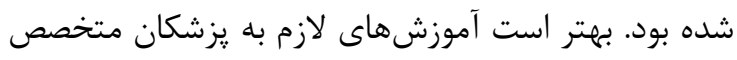

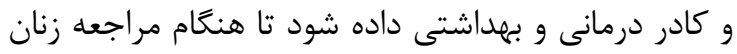

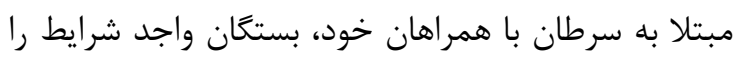

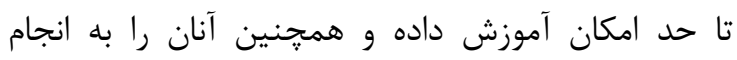

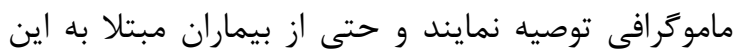


بستكان مبتلايان به سرطان يستان، يا همكارى مشروط از

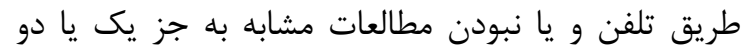

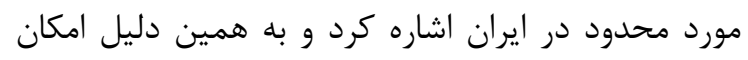
مقايسه نيز فراهم نشد.

\section{نتيجهكيرى}

نتايج كسب شده از مطالعه حاضر نشان داد كه بلهرغم

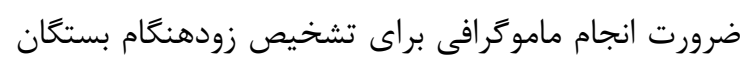
زنان مبتلا به سرطان يستان، آنان انجام غربالكرى و ورائ

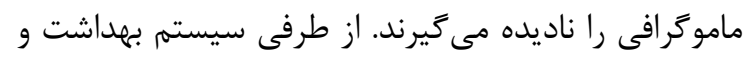

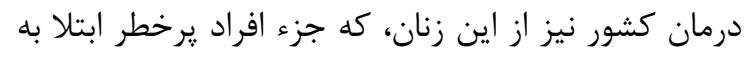
اين بيمارى مىباشند، غفلت مى كند. بنابراين رِيشنهان مىشود كه سيستم خدمات بهداشتى و درمانى كشور، بـاني

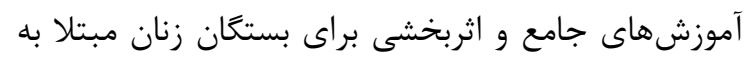

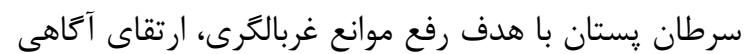

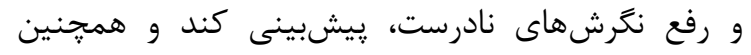

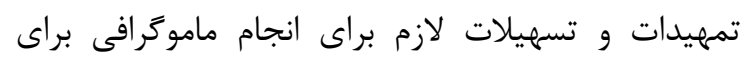
تشخيص زودهنگام اين بيمارى را فراهم نمايد.

تعارض منافع

نويسندًان اعلام مى دارند كه هيج تعارض منار منافعى در

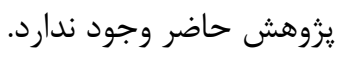

\section{References}

11. Arirchi I, Kolahdoozan S, Karbakhsh M, Chegini N, Mohseni SM, Montazeri A, Momtahen AJ, Kashefi A, Ebrahimi M. Twenty years of breast cancer in Iran: downstaging without a formal screening program. Annals of oncology. 2011; 22(1):937.

2. World Health Organization. Global health estimates: deaths by cause, age, sex and country, 2000-2012. Geneva, WHO. 2014

درجه 1 بيماران مبتلا به سرطان يستان؛ ترس، مسايل و مشكلات زندگى و عدم آكاهى كافى از دلايل اصلى عدم

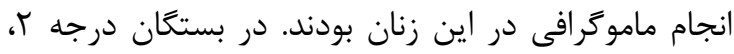
باورها و نخرشهاى نادرست، مسايل و مشكلات زندگى مافى و عدم آحاهى كافى از دلايل اصلى ذكر شده براى عدم انجام ماموگرافى بودند. در بررسى باورها و نخرشى اهـى داى نادرست نسبت به سرطان يستان و حتى انجام آزمايشات تشخيصى بـ بودي

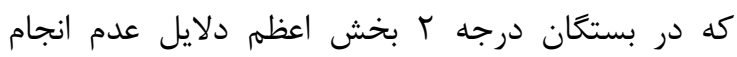

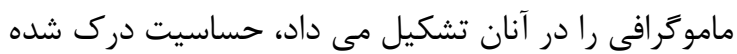

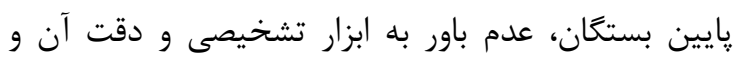

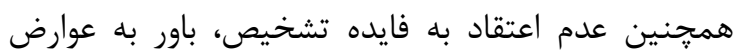

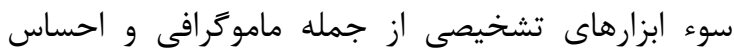
شرم و خجالت از دلايل اصلى ذكر شده بود. بورئ

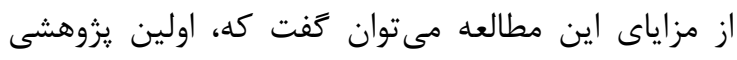
است كه دلايل عدم انجام ماموگرافى را در بستعان معان بيماران مبتلا به سرطان يستان، كه جزء گروههاى زيرخطر

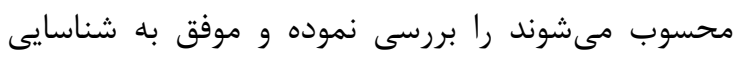
طيف بسيار وسيعى از دلايل عدم انجام ماموگرافى در آنان شده است. تاكنون مطالعهاى به اين وسعت و عمق در در ايران انجام نشده است. به نظر مىرسد با توجه به به نتايج

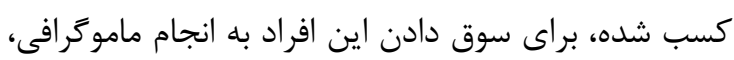

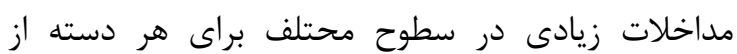

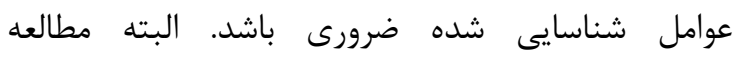

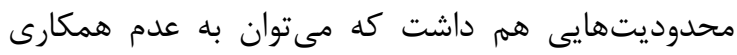

3. Region EM. Framework for health information systems and core indicators for monitoring health situation and health system performance. WHO. World Health Organization, Regional Office for the Eastern Mediterranean. 2016.

4. Rashidian H, Daroudi R, Ghiasvand R, Harirchi I, Zendehdel K. Prevalence and Incidence of premenopausal and postmenopausal breast cancer in Iran in 2010. 
Basic \& Clinical Cancer Research. 2013; 5(3):2-10.

5. Harirchi I, Karbakhsh M, Kashefi A, Momtahen AJ. Breast cancer in Iran: results of a multi-center study. Asian pacific journal of cancer prevention. 2004; 5(1):24-7.

6. Dixon JM, editor. ABC of breast diseases. John Wiley \& Sons; 2012.

7. Cardoso F, Kyriakides S, Ohno S, PenaultLlorca F, Poortmans P, Rubio IT, Zackrisson S, Senkus E. Early breast cancer: ESMO Clinical Practice Guidelines for diagnosis, treatment and follow-up. Annals of Oncology. 2019; 30(8):1194-220.

8. Amir E, Freedman OC, Seruga B, Evans DG. Assessing women at high risk of breast cancer: a review of risk assessment models. JNCI: Journal of the National Cancer Institute. 2010; 102(10):680-91.

9. Brausi M, Hoskin P, Andritsch E, Banks I, Beishon M, Boyle H, Colecchia M, DelgadoBolton R, Höckel M, Leonard K, Lövey J. ECCO essential requirements for quality cancer care: prostate cancer. Critical Reviews in Oncology/Hematology. 2020; 148:102861.

10. Sadr- Nabavi A, Dastpak M, HomaeiShandiz F, Bahrami AR, Bidkhori HR, Raeesolmohaddeseen M. Analysis of novel mutations in BRCA1 in Iranian families with breast cancer. Hereditas. 2014; 151(2-3):3842.

11. Avis NE, Smith KW, Link CL, Goldman MB. Increasing mammography screening among women over age 50 with a videotape intervention. Preventive medicine. 2004; 39(3):498-506.

12. Shiraly R, Asadollahi K, Asadollahi P. Risk perception and preventive issues for breast cancer among female employees. Iranian Journal of Cancer Prevention. 2010; 3(4): 16673.

13. Ferlay J, Colombet M, Soerjomataram I, Mathers C, Parkin DM, Piñeros M, Znaor A, Bray F. Estimating the global cancer incidence and mortality in 2018: GLOBOCAN sources and methods. International journal of cancer. 2019; 144(8):1941-53.

14. Montazeri A, Ebrahimi M, Mehrdad N, Ansari M, Sajadian A. Delayed presentation in breast cancer: a study in Iranian women. BMC women's health. 2003; 3(1):4.

15. Tazhibi M, Dehkordi ZF, Babazadeh S, Tabatabaeian M, Rezaei P, Faghihi M. Investigation of the age trends in patients with breast cancer and different sizes of tumors in Breast Cancer Research Center of Isfahan University of Medical Sciences in 2001-2010.
Journal of education and health promotion. 2014; 3 .

16. safa najafi, a.a., The need for genetic counseling in patients with breast cancer. Journal of Breast Diseases. 2009; 2(1):38-42.

17. Montazeri A, Ebrahimi M, Mehrdad N, Ansari M, Sajadian A. Delayed presentation in breast cancer: a study in Iranian women. BMC women's health. 2003; 3(1):4.

18. Kim JH, Kim O. Predictors of perceived barriers to mammography in Korean women. Asian Nursing Research. 2008; 2(2):74-81.

19. Bundred N, Dixon JM, Thomas J. Management of Regional Nodes in Breast Cancer. BMJ. 2013; 347.

20. Leeman J, Moore A, Teal R, Barrett N, Leighton A, Steckler A. Promoting community practitioners' use of evidencebased approaches to increase breast cancer screening. Public Health Nursing. 2013; 30(4): 323-31.

21. Hashemian M, Amin Shokravi F, Lamyian M, Hassanpour K, Akaberi A. Reliability and validity of the Champion's health belief model scale for mammography among Iranian women with family history of breast Cancer. Health Education and Health Promotion. 2013; 1(3):19-31.

22. Murillo R, Díaz S, Perry F, Poveda C, Pineros M, Sánchez O, Buitrago L, Gamboa O, Lozano $\mathrm{T}$, Yu $\mathrm{H}$, Wang $\mathrm{CY}$. Increased breast cancer screening and downstaging in $\mathrm{C}$ olombian women: A randomized trial of opportunistic breast- screening. International journal of cancer. 2016;138(3):705-13.

23. Wang JH, Schwartz MD, Brown RL, Maxwell AE, Lee MM, Adams IF, Mandelblatt JS. Results of a randomized controlled trial testing the efficacy of a culturally targeted and a generic video on mammography screening among Chinese-American immigrants. Cancer Epidemiology and Prevention Biomarkers. 2012; 21(11):1923-32.

24. Naghibi SA, Shojaizadeh D, Yazdani CJ, Montazeri A. Breast cancer preventive behaviors among Iranian women: a systematic review.

25. Ahmadian M, Samah AA, Emby Z. Barriers to mammography among women attending gynecologic outpatient clinics in Tehran, Iran. Scientific Research and Essays. 2011; 6(27): 5803-11.

26. Taymoori P, Habibi S. Application of a health belief model for explaining mammography behavior by using structural equation model in women in Sanandaj. Scientific Journal of Kurdistan University of Medical Sciences. 2014; 19(3):103-15. 
27. Ghazdehi MR, Amini L, Parvizi S, Hoseyni AF. Attitudinal Barriers to Mammography Screening among Women in Tehran, 2010. Journal of Mazandaran University of Medical Sciences (JMUMS). 2013; 23(99).

28. Farshbaf KA, Shahnazi M, Ghahvehchi A, Torabi S. Performance conditions of breast cancer screening methods and its efficient factors among women referring to health centers of Tabriz. 2009.

29. Calderón-Garcidueñas AL, Flores-Peña Y, De León-Leal S, Vázquez-Martínez CA, FaríasCalderón AG, Melo-Santiesteban G, ElizondoZapién RM, Hernandez-Hernandez DM, Garza-Moya R, Cerda-Flores RM. An educational strategy for improving knowledge about breast and cervical cancer prevention among Mexican middle school students. Preventive medicine reports. 2015; 2:250-4.

30. Akbari H, Jedi Arani T, Gilasi H, Moazami A, alin gholinpour A, azar abdar T. Study of motivational factors and causes of nonparticipation to breast and cervical cancer screening tests among women attending health centers in Kashan city. scientific journal of ilam university of medical sciences. 2014; 22(3):137-48.

31. Doumit MA, Huijer HA, Kelley JH, El Saghir $\mathrm{N}$, Nassar N. Coping with breast cancer: a phenomenological study. Cancer nursing. 2010; 33(2):E33-9.

32. Abedi HA. The application of phenomenological research methodology in clinical sciences. Rahbord J. 2010; 54(3): 20724.
33. Creswell JW, Clark VL. Designing and conducting mixed methods research. Sage publications. 2017.

34. Creswell JW, Clark VL, Gutmann ML, Hanson WE. Advanced mixed methods research designs. Handbook of mixed methods in social and behavioral research. 2003; 209:240.

35. Brislin RW. Research instruments. Field methods in cross-cultural research. 1986; 15962.

36. Rubin HJ, Rubin IS. Qualitative interviewing: The art of hearing data:Sage. 2011.

37. Shamsi M, Neyestani H, Ebrahimipour H, Esmaeili H, Nosrati M. Using social marketing model to persuade the women to do mammography. Journal of School of Public Health and Institute of Public Health Research. 2014; 12(1):85-96.

38. Harirchi I, Ebrahimi M, Zamani N, Jarvandi S, Montazeri A. Breast cancer in Iran: a review of 903 case records. Public health. 2000; 114(2):143-5.

39. Enjezab B, Mojahed S, Bokaee M. Barriers and motivators related to cervical and breast cancer screening. SSU_Journals. 2004; 12(3): 78-84.

40. Bastani R, Mojica CM, Berman BA, Ganz PA. Low-income women with abnormal breast findings: results of a randomized trial to increase rates of diagnostic resolution. Cancer Epidemiology and Prevention Biomarkers. 2010; 19(8):1927-36. 